\title{
Review
}

\section{Electromagnetic exploration of the oceanic mantle}

\author{
By Hisashi UTADA*1,†
}

(Communicated by Yoshio FukaO, M.J.A.)

\begin{abstract}
Electromagnetic exploration is a geophysical method for examining the Earth's interior through observations of natural or artificial electromagnetic field fluctuations. The method has been in practice for more than 70 years, and 40 years ago it was first applied to ocean areas. During the past few decades, there has been noticeable progress in the methods of instrumentation, data acquisition (observation), data processing and inversion. Due to this progress, applications of this method to oceanic regions have revealed electrical features of the oceanic upper mantle down to depths of several hundred kilometers for different geologic and tectonic environments such as areas around mid-oceanic ridges, areas around hot-spot volcanoes, subduction zones, and normal ocean areas between mid-oceanic ridges and subduction zones. All these results estimate the distribution of the electrical conductivity in the oceanic mantle, which is key for understanding the dynamics and evolution of the Earth together with different physical properties obtained through other geophysical methods such as seismological techniques.
\end{abstract}

Keywords: electromagnetic exploration, oceanic mantle, electrical conductivity, Earth internal structure, ocean bottom observation

\section{Introduction}

Interactions between the solar wind and the Earth's main magnetic field result in fluctuations in electric current systems in the magnetosphere and ionosphere. Geomagnetic field variations due to these fluctuating currents, penetrating into the Earth's interior, cause secondary currents within the Earth through electromagnetic (EM) induction, because the Earth is composed of partially conducting materials, which are not as conducting as metals, but much more so than insulators (Fig. 1). The relation between externally inducing and internally induced EM field variations is dependent on the material property (the electrical conductivity) governing the EM induction. Such a relation can be obtained by analyzing observed data of EM field variations, allowing the Earth's electrical structure to be examined. This is generally known as the EM induction method.

*1 Earthquake Research Institute, University of Tokyo, Tokyo, Japan.

${ }_{\dagger}$ Correspondence should be addressed: H. Utada, Earthquake Research Institute, University of Tokyo, Yayoi 1-1-1, Bunkyo-ku, Tokyo 113-0032, Japan (e-mail: utada@eri.u-tokyo. ac.jp).
In addition to the electrical conductivity, EM induction is controlled by the period (time scale) of the field fluctuations. The typical depth, $\delta$, of the EM field penetration for a given period, $T$, can roughly be estimated by the well-known relation of the skindepth, which is given as

$$
\delta=\sqrt{\frac{T}{\pi \mu_{0} \sigma}}=\sqrt{\frac{2}{\omega \mu_{0} \sigma}},
$$

where $\sigma$ is the electrical conductivity, $\mu_{0}$ is the magnetic permeability (assumed to be constant and equal to its value for a vacuum) and $\omega=2 \pi / T$ is the angular frequency. In the geomagnetic induction method, the target period range is chosen for the depth range in which the researcher is interested.

The phenomenon of EM induction was originally discovered by Michael Faraday in the 19th century. However, it was not used as a tool for Earth exploration until the mid 1950s when the theory of the magnetotelluric (MT) method was established. ${ }^{1)}$ Other researchers independently developed similar approaches. ${ }^{2), 3)}$ Now it is regarded as a practical geophysical means of exploring the interior of the Earth, because the electrical conductivity of the materials that compose the Earth is sensitive to physical and chemical conditions such as temper- 


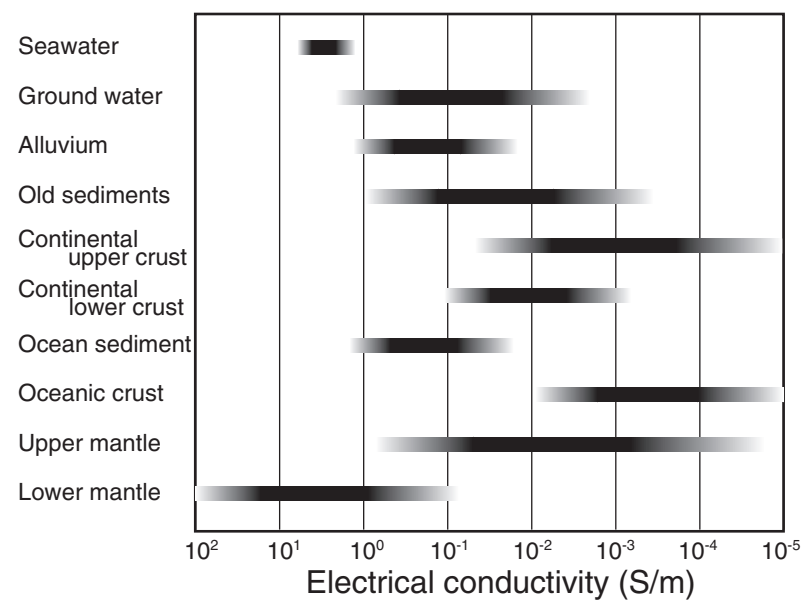

Fig. 1. Diagram showing the range of electrical conductivity for different layers of the Earth's interior.

ature, water content, oxygen fugacity, the presence of melts, and carbon content, all of which are useful in aspects of Earth science. A physical interpretation of such EM exploration results is made by referring to the measurements of the electrical conductivity of mantle materials in the laboratory with precise control of the physical and chemical conditions. Concerning recent advances in laboratory experiments and the related physical interpretations, however, fairly recent reviews are available. ${ }^{4), 5)}$ This paper, therefore, mostly focuses on the aspects of methodology including instrumentation and data inversion, which are essential to provide an accurate model of electrical structure.

In the MT method, the electrical conductivity distribution in the Earth is investigated by analyzing the spatial and frequency dependences of the impedance, which describes the linear relationship between the horizontal components of the electric and magnetic field variations. The relation is usually written in the frequency domain as

$$
\mathbf{E}_{h}(\mathbf{r}, \omega)=\mathbf{Z}(\mathbf{r}, \omega) \mathbf{H}_{h}(\mathbf{r}, \omega),
$$

where $\mathbf{E}_{h}$ and $\mathbf{H}_{h}$ are the horizontal electric and magnetic field variations vectors, respectively, $\mathbf{Z}$ is the impedance, generally given as a $2 \times 2$ tensor with complex elements, and $\mathbf{r}$ is the location of observation. Although less common than the MT method, EM induction is investigated by using similar linear relations between different components of the electromagnetic field variations. ${ }^{6}$ ) The coefficient of the linear relation, like that given in Eq. [2], is generally called the inductive response function. The frequency dependence of a response function for a given observation site can be estimated through spectrum analysis $^{7)}$ of obtained time series data for the EM field components.

In the case of dealing with a period shorter than around one day, the lateral scale of the externally inducing field is much larger than the penetration depth given by Eq. [1]. In such a situation, the Earth's surface can be considered flat and the inducing field laterally uniform. Here the Earth is regarded as a half space, and the Cartesian coordinate system is used to solve the governing equations (Maxwell's equations). This treatment is known as regional/local induction. Again, under the assumption of a uniform Earth with conductivity $\sigma_{0}$, the impedance becomes a unique scalar independent of the observation site and can be written explicitly as

$$
Z_{0}(\omega)=\sqrt{\frac{i \omega \mu_{0}}{\sigma_{0}}} .
$$

This means that if the Earth's conductivity is spatially uniform, the impedance is determined simply by Eq. [3] and the phase is always 45 degrees.

We can rewrite Eq. [3] as

$$
\sigma_{0}=\frac{i \omega \mu_{0}}{Z_{0}(\omega)^{2}} .
$$

This implies that the Earth's conductivity can be estimated by simply considering a pair of mutually orthogonal electric and magnetic components at an arbitrary site. A simple analytical expression for the scalar impedance was derived in $1953^{1)}$ for a model Earth consisting of laterally uniform layers with different conductivities, which is called a one-dimensional (1D) Earth model. In reality, the Earth is neither uniform nor horizontally stratified, meaning a general treatment of the impedance tensor and other response functions at a number of stations covering the area of interest is required in practice. The heterogeneous distribution of electrical conductivity is estimated such that the theoretically predicted impedance elements fit those observed in a least squares sense. There has been significant progress in this field over the past few decades. ${ }^{8)-12)}$

One of the difficulties associated with EM explorations, compared with imaging methods using seismic waves, is that the observed quantity is not a propagating wave but a diffusing field. Therefore, the spatial resolution is not determined simply by the observation site spacing but also by the frequency of the field fluctuation. This can be understood by considering the EM induction of a conducting body 
in a host medium with a conductivity difference $\Delta \sigma$ and a scale of $L$ by a uniform EM field with an angular frequency $\omega$. In this situation, the theory of EM induction tells us that significant induction occurs only when the non-dimensional induction number,

$$
M=\sqrt{\frac{\omega \mu_{0}|\Delta \sigma| L^{2}}{2}},
$$

is greater than unity. ${ }^{13)}$ This means that a given set of EM observations for a given angular frequency range can image heterogeneities greater than a minimum scale $L_{\min }$ as given by an expression similar to the skin depth [1]:

$$
L_{\text {min }} \approx \sqrt{\frac{2}{\omega_{\max } \mu_{0}|\Delta \sigma|}}
$$

Here $\omega_{\max }$ is the highest frequency of the observation. Therefore, when the heterogeneous Earth is explored, the minimum scale as given by [6] is roughly the available spatial resolution. To avoid spatial aliasing, the typical site spacing has to be smaller than this minimum scale. On the other hand, an observation array should cover a wider area for better imaging of the target structure. Thus, we try to optimize the observation design (the frequency range and distribution of observation sites) by taking these relations into consideration, because the number of available instruments is often limited.

In the years following the establishment of geomagnetic induction, observations were made on land because it was desirable to explore mineral resources, ground water distribution, sedimentary basins, and structures of continental crust and mantle. ${ }^{14)-16)}$ Although its application to seafloor exploration had been suggested in one of the earliest papers on the magnetotelluric method, ${ }^{1)}$ actual measurements of electric and magnetic field variations required significant instrumental development. ${ }^{17)-20)}$ After the seafloor EM exploration technique became practical, the most important finding from the ensuing works was the presence of a highly conducting layer in the oceanic upper mantle, ${ }^{21)-23)}$ the depth of which may be dependent on the age of the oceanic plate, in a similar manner to the seismic low velocity layer. ${ }^{24)}$

Although the lithosphere and asthenosphere have to be distinguished by the viscosity, imaging the Earth's structure in terms of viscosity provides only weak resolution even with the most recent technology, ${ }^{25)}$ compared with seismic or electromagnetic imaging methods. For this reason, seismic and electromagnetic imaging methods are applied to the study of the structure of the lithosphere and asthenosphere systems; both the low seismic velocity and high electrical conductivity below the oceanic plate were regarded as characteristics of the oceanic asthenosphere as a result. So far several origins have been proposed following studies of mineral physics for the low seismic velocity, high electrical conductivity and low viscosity of the asthenosphere, ${ }^{24), 26)-31)}$ yet a consensus has not been reached. ${ }^{32), 33)}$

The present paper aims to review methodological advances in observational studies on the electrical conductivity distribution in the oceanic mantle. Some of the contents have been already reported in previous reviews, ${ }^{34)-38)}$ so only the important points are summarized in such cases. Following Introduction, Section 2 briefly introduces the instrumentations used in modern explorations of the oceanic mantle. Section 3 describes the basics of modeling and inversion. Major results from recent studies are reviewed in Section 4, and then remaining questions are discussed.

\section{Instruments for studying oceanic mantle}

In the developmental stage, extensive efforts were made to overcome a number of difficulties and realize seafloor measurements for EM exploration, such as pressure housings to protect parts of the instrument from the high water pressure, pressuretight connectors, recovery systems, compact and accurate magnetic sensors, highly accurate systems to measure the electric field, batteries large enough to supply electricity for the required recording time, and memory to record high volumes of data. ${ }^{39)}$ Due to these difficulties, earlier models of seafloor instruments were designed specifically for either magnetic or electric field measurements. ${ }^{17)}{ }^{-20)}$ Such instruments were called either OBMs (ocean bottom magnetometers) or OBEs (ocean bottom electrometers), respectively. Finally most of the technological challenges were overcome, and a new instrument was developed ${ }^{40), 41)}$ that measures five components of EM field variations (three magnetic and two horizontal electric components) on the seafloor.

Figure 2a shows an example of the ocean bottom electro-magnetometer (OBEM) that is currently used by the author's group (see Table 1 for its typical specifications). It consists of two pressure housings made of glass spheres $45 \mathrm{~cm}$ in diameter, four plastic arms for electric field measurements, and an acoustic release system with a concrete anchor, all of which are held together by a titanium frame. One of 

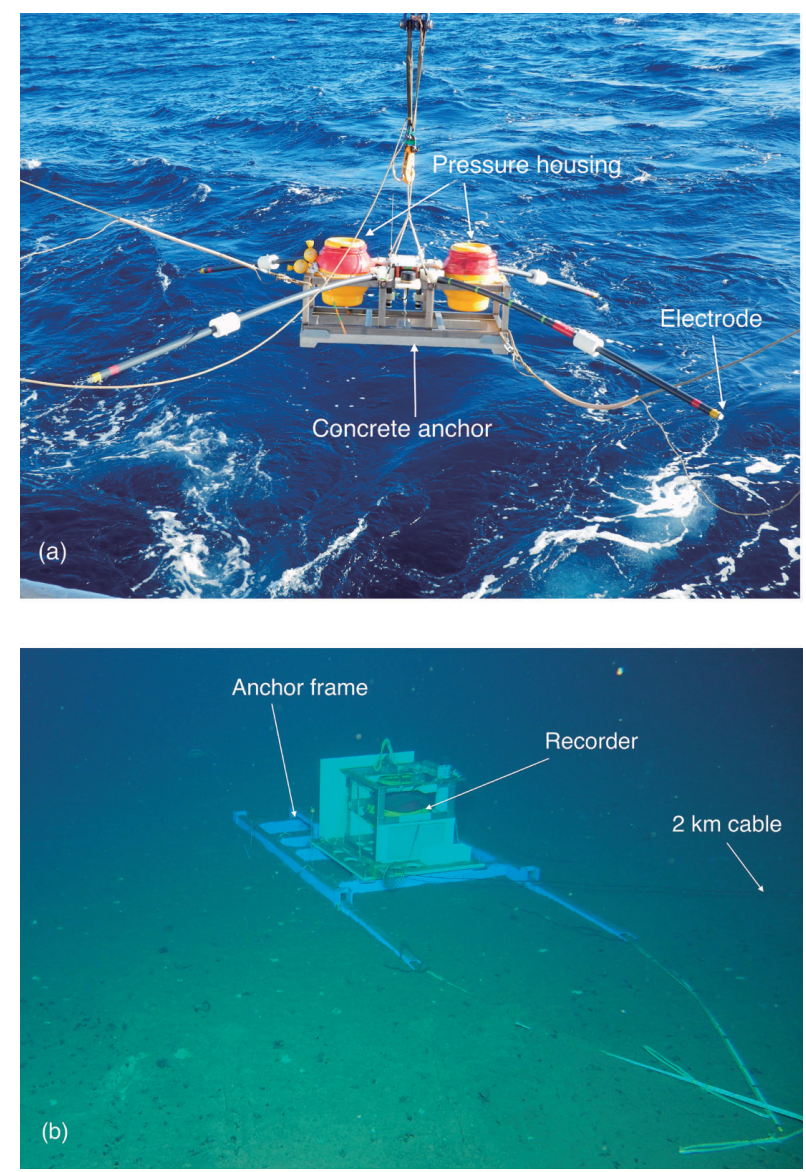

Fig. 2. (a) Deployment of ocean bottom electro-magnetometer (OBEM) from a research vessel. A three-component magnetometer, electronics and batteries are contained in two pressure housings (with yellow tops). Two components of the electric field variations are measured as a voltage difference between two pairs of electrodes, each of which is fixed at the end of a plastic arm. The two pressure housings are held by a rigid frame made of titanium alloy, and a concrete anchor is attached to the bottom of the frame. On recovery, the anchor is released following an acoustic command. (b) A photo of EFOS installed on the 5800-m-deep seafloor in the northwestern Pacific Ocean. This photo was taken from the ROV (Remotely Operated Vehicle) KAIKO-7000II (JAMSTEC) when she approached the site to recover the recorder.

the pressure housings contains lithium battery cells sufficient for approximately 1.5 years' recording at a sampling interval of one minute. This is necessary recording length to obtain MT impedance estimates at periods up to 1 day with error level of a few $\%$ of the off-diagonal and $5-10 \%$ of the diagonal elements for reliable 3-D inversion of the upper mantle structure. The other housing contains a threecomponent fluxgate magnetic sensor with a twocomponent tilt sensor, its electric circuit, an amplifier
Table 1. Specifications of the ocean bottom electro-magnetometer (OBEM) developed by the research group at the Earthquake Research Institute of the University of Tokyo

\begin{tabular}{ll}
\hline Item & Typical value \\
\hline Resolution of magnetic components & $0.01 \mathrm{nT}$ \\
Resolution of electric components & $0.003 \mu \mathrm{V} / \mathrm{m}$ \\
Resolution of tilt components & $0.86 \operatorname{arc~sec}$ \\
Tilt allowance & $< \pm 8$ degrees \\
Sampling interval & 1 minutes or $1 \mathrm{sec}$ \\
& (programmable) \\
Maximum depth of deployment & $6,500 \mathrm{~m}$ \\
Power consumption & $3 \mathrm{~W}$ (average) \\
Data storage & $20 \mathrm{~GB}$ Max \\
\hline
\end{tabular}

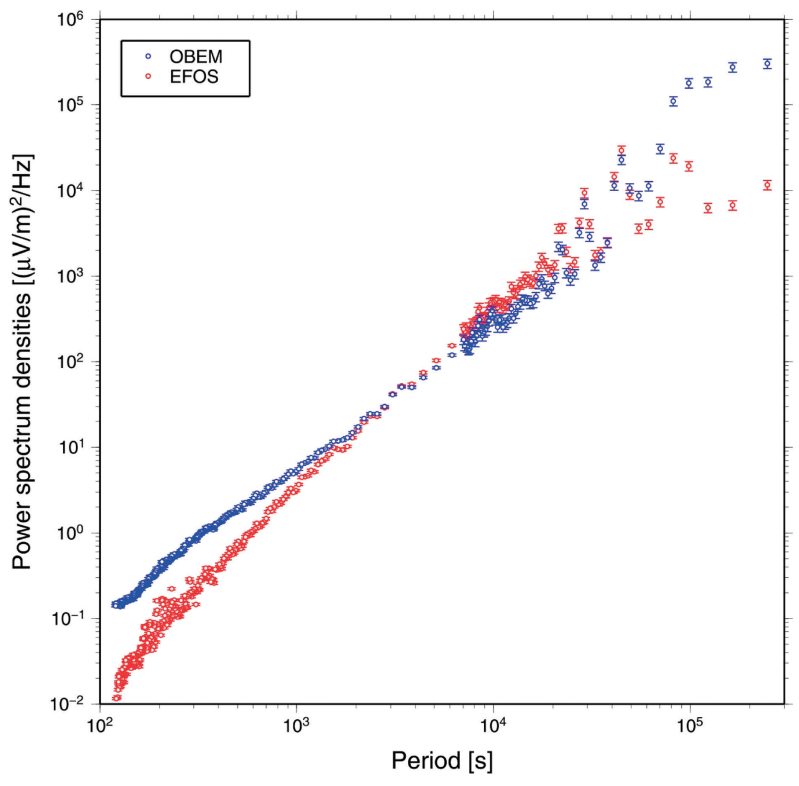

Fig. 3. Comparison of power spectra calculated from six months' simultaneous records of electric field variations obtained by the prototype EFOS (red symbols) and an OBEM (blue symbols) installed near each other. The experiment was carried out in the Philippine Sea in 2005. ${ }^{46}$ )

for the two-component electric field measurement, a temperature sensor and a data recorder. At the end of each arm, a silver silver-chloride $(\mathrm{Ag}-\mathrm{AgCl})$ electrode $^{18), 39)}$ is attached and the two orthogonal horizontal components of the electric field are measured as voltage differences between each pair of electrodes, which are separated by about $4 \mathrm{~m}$. An electrode of this type is used exclusively for marine measurements because it exhibits much lower noise and long-term drift in voltage relative to the seawater than any other electrode. ${ }^{39)}$ 
There is alternative type of OBEM equipped with a coil system for the magnetic sensor. ${ }^{42)}$ Because of the frequency characteristics of the sensor, this instrument was originally developed for explorations of relatively shallower depth such as petroleum exploration. However they were also used for studying structures of uppermost oceanic mantle.

The OBEM is deployed by free fall from a ship, and recording automatically begins after landing on the seafloor. It stays on the seafloor for one year or more in most cases, to obtain accurate and precise estimation of the EM response functions. ${ }^{43)}$ To recover the instrument, the concrete anchor is released in response to an acoustic command from the ship. Starting in 1990, it took us about five years to develop the OBEM, ${ }^{41)}$ which was then deployed in the deep ocean for the first time in the MELT (Mantle Electromagnetic and Tomography) experiment, ${ }^{44), 45)}$ an international project to explore the mantle structure using seismic and electromagnetic methods beneath the spreading center of the East Pacific Rise. Similar instruments were developed more or less independently and are presently being used by research groups in the US, France, Germany and Japan.

The electric field of the Earth is measured as a voltage difference between two grounded electrodes. Each electrode is connected to a measuring apparatus by an insulated cable. This acts as an antenna of which the effective length is the electrode separation. Because the wavelength of the signal (the EM field variations) is so long (much longer than the antenna), we can expect a higher signal-to-noise ratio and stability for measurements with larger electrode spacing, as long as electrodes with the same characteristics are used. However, most existing instruments measure the electric field with a short electrode separation (less than $10 \mathrm{~m}$ ) due to the technological difficulty in laying a cable over a long distance in the deep ocean, although such a measurement was already suggested in the classical paper. ${ }^{1)}$ In a recent development ${ }^{46)}$ of EFOS (Earth's electric Field Observation System), this problem was solved by using a submersible, which enables recording of the electric field with a typical electrode separation of $1-10 \mathrm{~km}$. Figure $2 \mathrm{~b}$ is an actual view of EFOS installed on the deep seafloor equipped with a $2 \mathrm{~km}$ long cable. The pressure housing of the EFOS recorder is the same glass sphere as that used for OBEM, and is large enough to hold lithium cells sufficient for recording at a sampling interval of one second for as long as four years. The comparison of electric field spectra simultaneously obtained by OBEM and EFOS (Fig. 3) indicates that EFOS data contains lower noise than OBEM data for periods longer than one day and shorter than approximately $1000 \mathrm{~s}$. In the range between these periods, the electric field noise of OBEM is sufficiently low. Thus EFOS provides electric field data of higher quality than OBEM for the measurement of signals both at relatively high frequencies, which is sensitive to shallower structures, and at very low frequencies, which provides information about the Earth's deep interior.

\section{Modeling and inversion methods}

Forward modeling of EM observations is made by solving Maxwell equations for a given distribution of the electrical conductivity within the Earth, under a $1 \mathrm{D}$ or $2 \mathrm{D}$ approximation or a full 3D consideration. In most cases, the forward problem is solved in the frequency domain. Because of the high conductivity of seawater (Fig. 1), EM signals measured at the seafloor due to external current systems are more strongly attenuated for shorter periods. Therefore, signal detection in the deep sea is limited to periods longer than several hundred seconds. ${ }^{39)}$ At such low frequencies, the displacement current term in Maxwell equations can be neglected, so that we have a set of equations,

$$
\begin{aligned}
& \nabla \times \mathbf{E}(\mathbf{r}, \omega)=-i \omega \mu_{0} \mathbf{H}(\mathbf{r}, \omega) \\
& \nabla \times \mathbf{H}(\mathbf{r}, \omega)=\sigma(\mathbf{r}) \mathbf{E}(\mathbf{r}, \omega)+\mathbf{J}_{e x t}(\mathbf{r}, \omega),
\end{aligned}
$$

where $\mathbf{J}_{\text {ext }}$ denotes the external source current density. These equations are solved either in a Cartesian (Fig. 4a) or spherical coordinate system for regional/local or global induction problems, respectively. Relations of the skin-depth [1] and the impedance [3] can be obtained from [7], assuming a $1 \mathrm{D}$ simplification where every variable in [7] changes only in the vertical direction.

It is possible to directly compare each field component of the calculated EM fields with the observed counterparts to estimate the electrical conductivity distribution in the Earth. However, in most cases, response functions are obtained as the ratio of EM field components from a set of forward solutions of [7], and are then compared with those estimated from observed data. For example, the impedance [2] is defined as the ratio of the electric to magnetic field components. The amplitude of the electric and magnetic field solutions of [7] is proportional to the amplitude of the source current and this proportionality is cancelled by taking the 


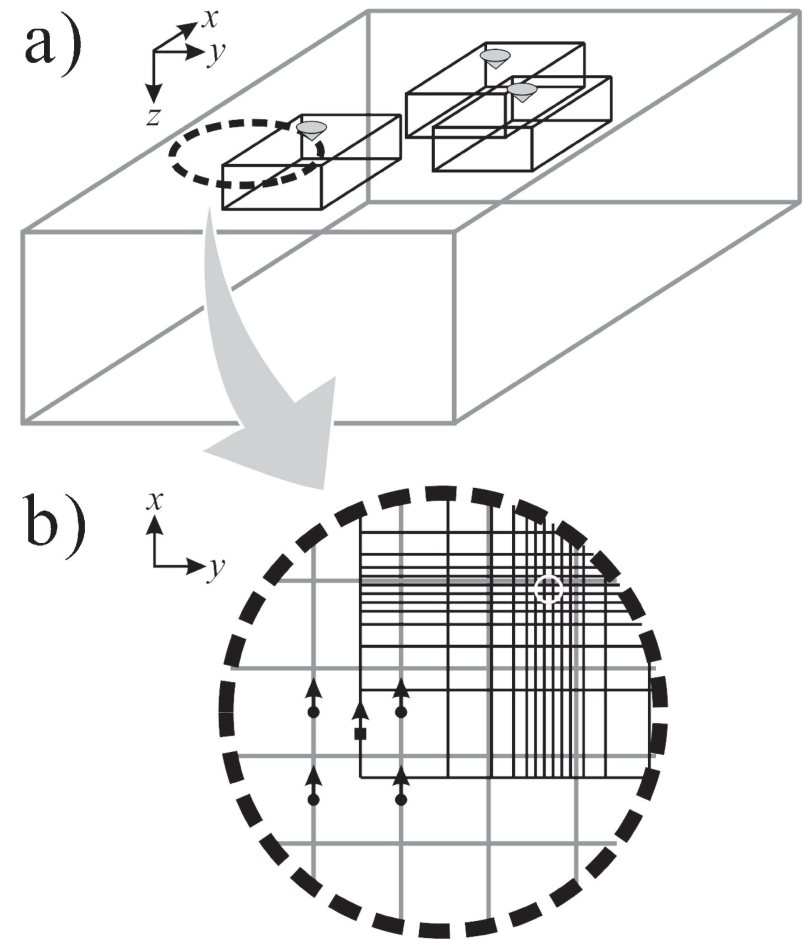

Fig. 4. Incorporation of large-scale and small-scale models of seafloor topography in $3 \mathrm{D}$ inversion procedure. ${ }^{64)}$ (a) The large model (gray box) covers all observation sites (inverted cones) with moderate-dimension numerical blocks, which are used for the first stage of modeling. The small models (black boxes) are prepared for each observation site with finer numerical blocks, which are used for the second stage of modeling. (b) Horizontal grids of the large (gray lines) and small (black lines) models. The initial and boundary values of the magnetic field to be solved in the second stage of modeling (arrow with square tails) are obtained through bi-linear interpolation of the four surrounding values (arrows with circle tails), which is the solution of the first stage.

ratio. Therefore, response functions obtained at different times can be used in modeling or inversion. This is one of the advantages of using response functions.

In general, modeling seafloor EM induction is difficult because of the strong induction effects from the seafloor topography. ${ }^{47)}$ Large conductivity contrasts also exist in coastal regions. It has also been pointed out that coastlines will have irregular effects (mostly galvanic in this case) that may affect distant seafloor EM observations. ${ }^{48)}$-50) These complicated situations require the numerical modeling of seafloor induction to have fine discretization and to consider wide areas including distant coastlines, increasing the computational cost. In spite of the rapid progress in computer performance, it is not practical to incorpo- rate all these complexities into one numerical model. Thus, the model was separated into two parts: one to evaluate only the near-surface effects (topographic and coastline effects) and the other to evaluate EM induction due to the deep conductivity distribution. While the overall approach has to be 3D, it was found that the deep structure can be obtained through 1D or $2 \mathrm{D}$ treatment, if near-surface effects are evaluated rigorously in $3 \mathrm{D}$ and removed from the observed responses. ${ }^{51)-53)}$ This method is regarded as the most cost-effective. ${ }^{54), 55)}$

In order to obtain a model of the electrical conductivity distribution that explains the features of the observed EM response functions, we need to solve an inverse problem so as to minimize the objective functional that can formally be written $\mathrm{as}^{56)}$

$$
\phi(\mathbf{m})=\phi_{d}\left(\mathbf{d}_{o b s}, \mathbf{m}\right)+\lambda \phi_{m}\left(\mathbf{m}, \mathbf{m}_{0}\right),
$$

where $\phi_{d}$ and $\phi_{m}$ are the data and model objective functionals, respectively, $\mathbf{d}_{o b s}$ and $\mathbf{m}$ are vectors containing all the complex-valued response functions observed and model parameters to be determined (electrical conductivity), respectively, $\mathbf{m}_{0}$ is an a priori model and $\boldsymbol{\lambda}$ is the hyper parameter that controls the contribution from the model constraints. The data objective functional is the total misfit between the observed and calculated responses, which can be written as

$$
\phi_{d}\left(\mathbf{d}_{o b s}, \mathbf{m}\right)=\left\|\mathbf{W}_{d}\left[\mathbf{d}_{o b s}-\mathbf{A}(\mathbf{m})\right]\right\|^{2},
$$

where $\|\cdot\|$ is the two-norm, $\mathbf{W}_{d}$ is the data covariance matrix and $\mathbf{A}$ is an operator generating model responses from the model parameters based on Maxwell's equations. The model objective functional describes the regularization term that constrains the model parameters with the aid of an a priori model, and can be written as

$$
\phi_{m}\left(\mathbf{m}, \mathbf{m}_{0}\right)=\left\|\mathbf{W}_{m}\left(\mathbf{m}-\mathbf{m}_{0}\right)\right\|^{2},
$$

where $\mathbf{W}_{m}$ is the model covariance matrix expressing the model constraint. The model covariance consists of a spatial finite difference approximation of the gradient or Laplacian operator in most cases to ensure that the model parameter is spatially smooth. Recently, another kind of model constraint has also been considered for imaging sharp conductivity interfaces. ${ }^{57)}$

The inverse problem searches a set of parameters that minimizes the objective functional [8] through an iterative procedure. In this approach, the most time-consuming process is to calculate the gradient of the data objective functional with respect to the 
model parameter. Because of this difficulty, as well as insufficient computer performance, EM studies have long been using $2 \mathrm{D}$ inversion that creates a cross-sectional model of the electrical conductivity distribution. ${ }^{16), 58)}$ However, this difficulty can be greatly relieved by applying the so-called adjoint approach, ${ }^{8), 59)}$ which reduces computational loads so that a $3 \mathrm{D}$ inversion is feasible. ${ }^{10), 56)}$ At present, several inversion codes are available and are widely used for regional exploration on land. ${ }^{60)-62)}$ Although there still remained the problem in treating the seafloor topography and coast effects as shown above, this has recently been overcome to some extent by combining an inverse model that incorporates effects from large scale topography and coastlines with local forward modeling for the correction of small scale topographic effects (Figs. 4b and 4c). ${ }^{63)-65)}$ Further development of inversion methods is in progress.

\section{Progress in EM exploration of oceanic mantle}

In this section, progress in oceanic mantle studies using EM methods is reviewed. The MELT experiment $^{45}$ began a new stage of marine EM exploration. Before MELT, experiments only used a small number of seafloor instruments deployed for a few months along a line. From the data obtained, subsurface conductivity models were obtained simply through $1 \mathrm{D}$ or $2 \mathrm{D}$ inversions. ${ }^{21), 23), 66)-68)}$ Our present knowledge suggests that a recording length of several months is not enough for an accurate and robust estimation of MT impedances for the periods up to 1 day. In addition, inversion analyses were carried out without considering the 3D effects of topography and coastlines. As a result, the observations only gave us a vague image of the oceanic mantle structure, revealing large-scale features such as the presence of a highly conductive layer that possibly corresponds to the asthenosphere or back-arc spreading. The only exception is the EMSLAB experiment, ${ }^{69)}$ in which 18 seafloor stations were deployed in a $2 \mathrm{D}$ array on the Juan de Fuca oceanic plate together with many land observation sites along the west coast of the US and Canada. ${ }^{70)}$ However, the recording duration was restricted to two months because of the limited data storage devices available at that time. Although the observed responses were interpreted by $2 \mathrm{D}$ forward modeling because of these limitations, the resulting electrical conductivity 2D cross section provided extensive tectonic information associated with the subduction of the Juan de Fuca plate beneath the North American plate. ${ }^{71)}$
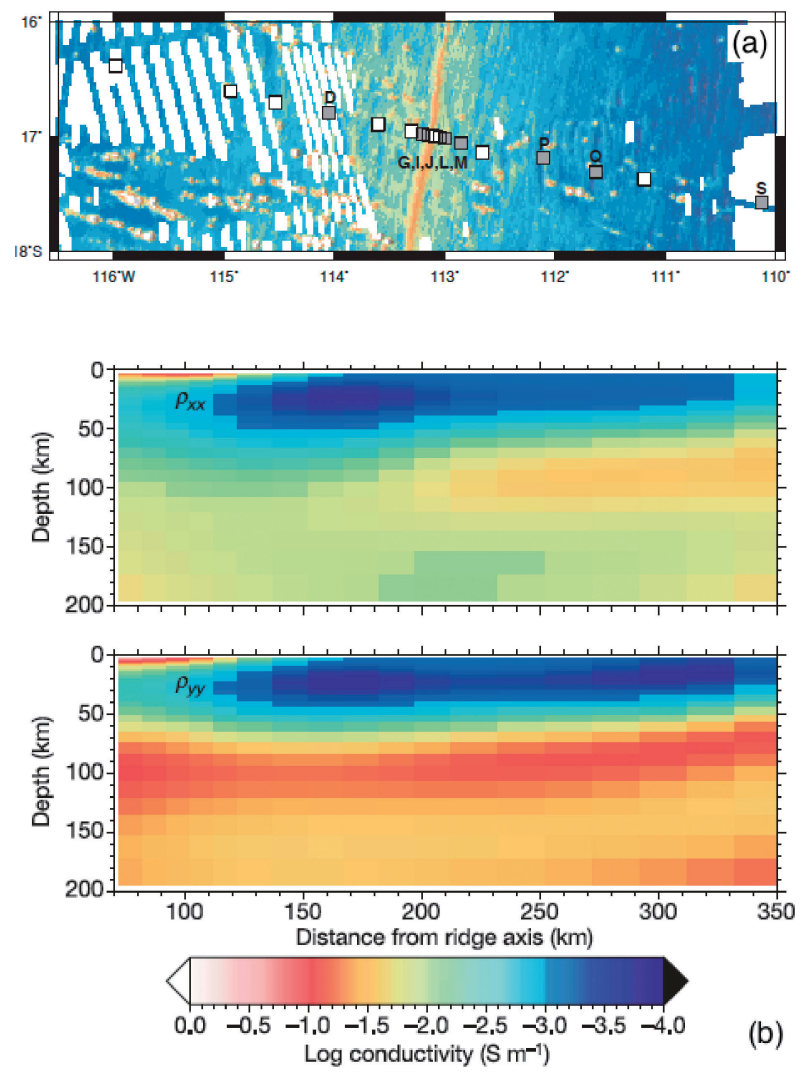

Fig. 5. (a) Map of the EPR near 17 degrees S showing the southern of two lines of sea-floor MT sites occupied during the MELT Experiment. The MT array was aligned perpendicular to the strike of the ridge to maximize the two-dimensionality of the experiment. The station names in the map refer to the locations of the magnetometers used for MT tensor estimation for $2 \mathrm{D}$ inversion. $^{45)}$ (b) Two model cross sections of conductivity through the region $70-350 \mathrm{~km}$ east of the southern East Pacific Rise in the MELT area. ${ }^{72)}$ The two sections show conductivity in the ridge-parallel $(\mathrm{x})$ direction (top) and plate spreading (y) direction (bottom). The key features in the model are the resistive layer above about $60 \mathrm{~km}$ in depth and the underlying conductive region that extends to about $120 \mathrm{~km}$ in depth. The high conductivity region is more conductive in the direction of plate spreading.

4.1 EM explorations beneath young oceanic plates near mid oceanic ridges. In the MELT EM experiment, a line of 19 sites at approximately 17 degrees $\mathrm{S}$ (the southern line) and a line of 12 sites at approximately 15.5 degrees $\mathrm{S}$ (the northern line) in the East Pacific Rise (EPR) region were deployed in June 1996 (Fig. 5a), and instruments were successfully recovered from 11 sites and eight sites along the respective lines one year later. The study area is known as a super fast spreading segment of the EPR, and the experiment focused on revealing the upper mantle structure below the very young oceanic crust 
within an age of roughly 1.3 Ma. The initial scientific report from this experiment ${ }^{45)}$ showed an asymmetric feature of the upper mantle structure between the east and west of the EPR. Subsequently, more detailed imaging results for the southern line were published, in which not only isotropic but also anisotropic inversion (Fig. 5b) was attempted after the correction for 3D topographic effects. ${ }^{72), 73)}$ The major findings of the MELT EM experiment can be summarized as follows. The anisotropic model shows a slightly better fit to the observation. The anisotropic inversion detected a highly conductive narrow sheet below the ridge axis with width of 10 $20 \mathrm{~km}$ and enhanced conductivity along the vertical axis. Except near the ridge axis, both the isotropic and anisotropic models exhibit a flat resistive layer down to the depth of $60 \mathrm{~km}$ in the uppermost mantle. Below this resistive layer, the conductivity is enhanced at depth of 60-120 and shows anisotropy with higher conductivity in the direction of plate spreading.

Electrical imaging was attempted at the northeastern EPR by using instruments with coil magnetic sensor. ${ }^{74)}$ Twenty-nine instruments were deployed along a line in parallel to the plate spreading and crossing the EPR at 9.5 degrees $\mathrm{N}$, and electrical structure was studied by $2 \mathrm{D}$ anisotropic inversion. Because of the sensitivity of the magnetic sensor used in this study, the inversion constrained the shallower upper mantle structures down to about $160 \mathrm{~km}$ and imaged a distinct high conductivity anomaly right beneath the ridge axis, spreading at 20-90 depths. Anisotropy is mostly insignificant, except at depths $10-20 \mathrm{~km}$ below the ridge where conductivity is highest in the vertical direction.

These results were obtained through careful and quantitative applications of various methods of forward modeling, inversion and statistical tests. The only remaining question is how the $2 \mathrm{D}$ assumption affected the features found. In fact, the $2 \mathrm{D}$ inversion result of the MELT northern line shows qualitatively similar but quantitatively different features, ${ }^{75)}$ which means the structure is not completely 2D. Also it is generally difficult to distinguish anisotropic features of observed MT impedances due to the intrinsic anisotropy of conductivity from those due to lateral heterogeneity so far as data along a line are inverted. Further study using a 2D array (not an array along a line) is necessary to deepen the understanding of the mid-oceanic ridge processes.

4.2 EM explorations beneath hotspot islands. Oceanic plates are created at spreading ridges and

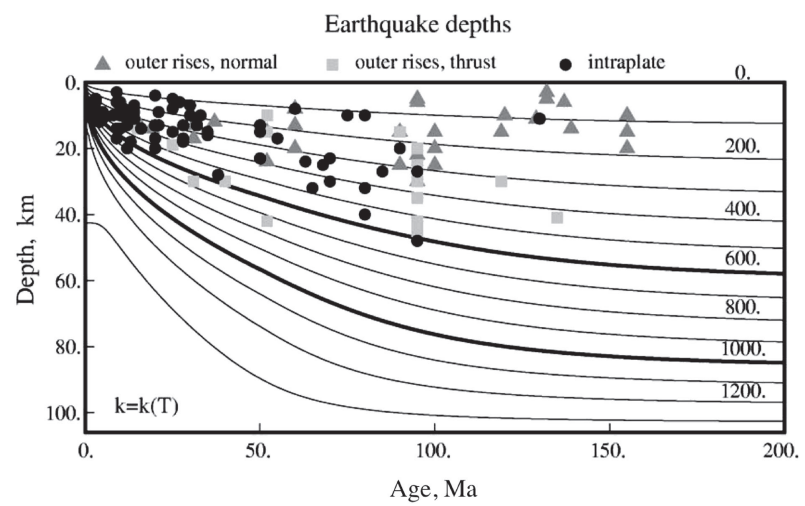

Fig. 6. The temperature contours in the oceanic mantle vs. plate age, calculated from the numerical solution that best fits the analytic solution for a cooling plate. ${ }^{76)}$ The 600 and $1000{ }^{\circ} \mathrm{C}$ isotherms are marked by thick lines. The points show the depths of intraplate earthquakes within the oceanic lithosphere whose depths have been constrained by waveform modeling. ${ }^{77}$

then move horizontally before going back into the mantle at the subduction zone. While an oceanic plate is moving horizontally, its thickness increases as it ages due to cooling. In such a system, the thermal structure in the upper mantle can be approximately estimated by a cooling plate model ${ }^{71), 76)}$ as shown in Fig. 6. This figure shows that the seismicity is restricted at the shallower (colder) part of the oceanic mantle, which corresponds to the oceanic lithosphere. Hot spot volcanic activity brings additional heat to this simple cooling process. Although the concept of such hot spots was proposed in earlier works ${ }^{78), 79)}$ and is well accepted by the Earth Science community, direct information as obtained through geophysical explorations is still limited in terms of the size and shape of the mantle plumes, their upwelling velocity, their source depth, and the depth at which the initial melting occurs. ${ }^{51)}$ For this reason, electrical imaging of the upper mantle below hot spot islands is an area of interest, and a few experiments have been attempted in recent years.

In 1997 a seafloor MT sounding experiment was carried out between April and December in the southwestern part of the Hawaiian hot-spot swell, in which EM data were collected at seven seafloor sites as indicated in Fig. 7a. ${ }^{80)} \mathrm{A} 2 \mathrm{D}$ inversion analysis of the observed EM responses revealed a narrow (radius $<100 \mathrm{~km}$ ), conducting (about $0.1 \mathrm{~S} / \mathrm{m}$ ) 'plume-like' anomaly which appears to connect the surface of the islands to the highly conducting $(\sim 1 \mathrm{~S} / \mathrm{m})$ lower mantle (Fig. $7 \mathrm{~b})$. For the treatment of the 3D topographic effects, the authors applied a tensor decomposition method. ${ }^{81)}$ However, present 

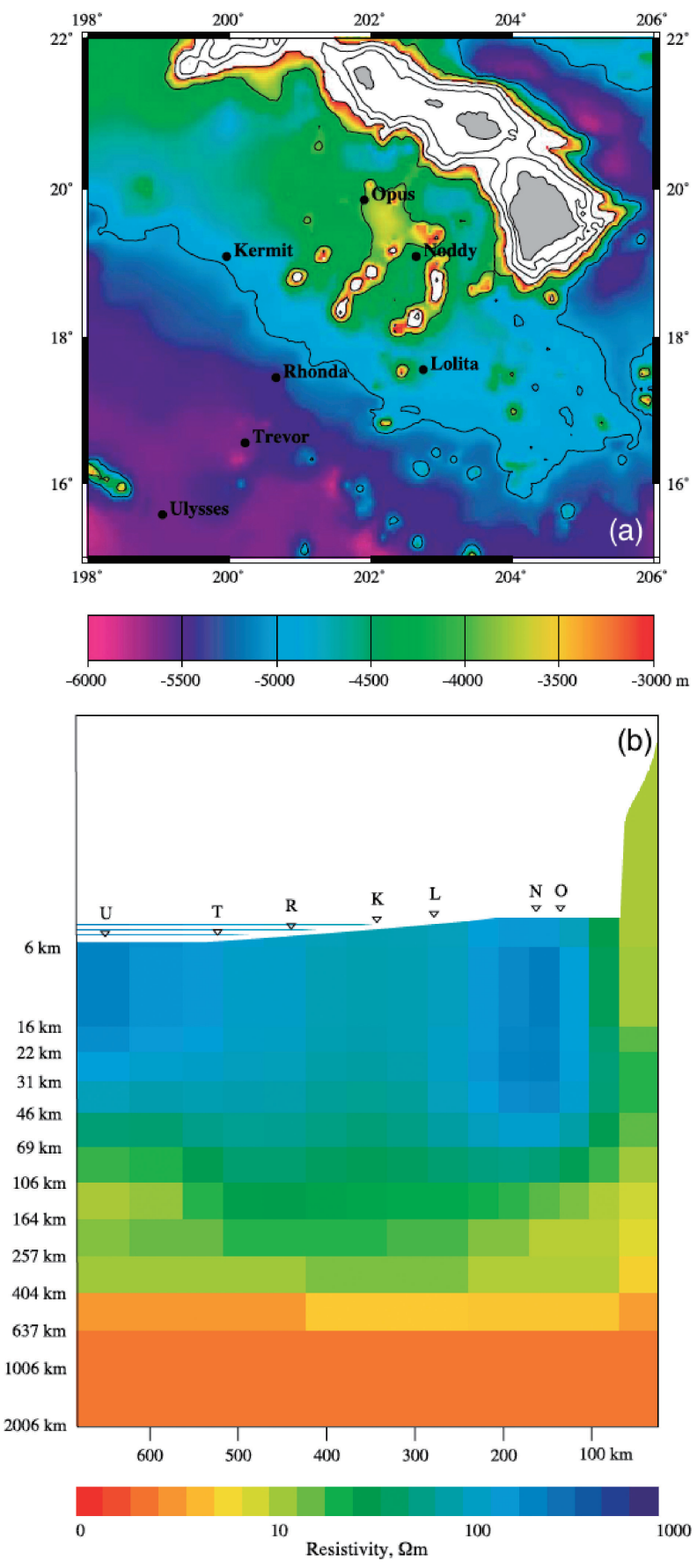

Fig. 7. (a) Location of the seven seafloor EM instruments deployed to the southwest of the Hawaiian Hot Spot. ${ }^{80)}$ All returned magnetic data, but only one channel of electric field data was recorded at site $\mathrm{L}$. The edge of the swell is approximately given by the $5000 \mathrm{~m}$ depth contour. (b) 2D model obtained by smooth inversion of seafloor EM data from the seven sites. ${ }^{80)}$ The island chain is represented by a ridge coming to within $300 \mathrm{~m}$ of the sea surface.

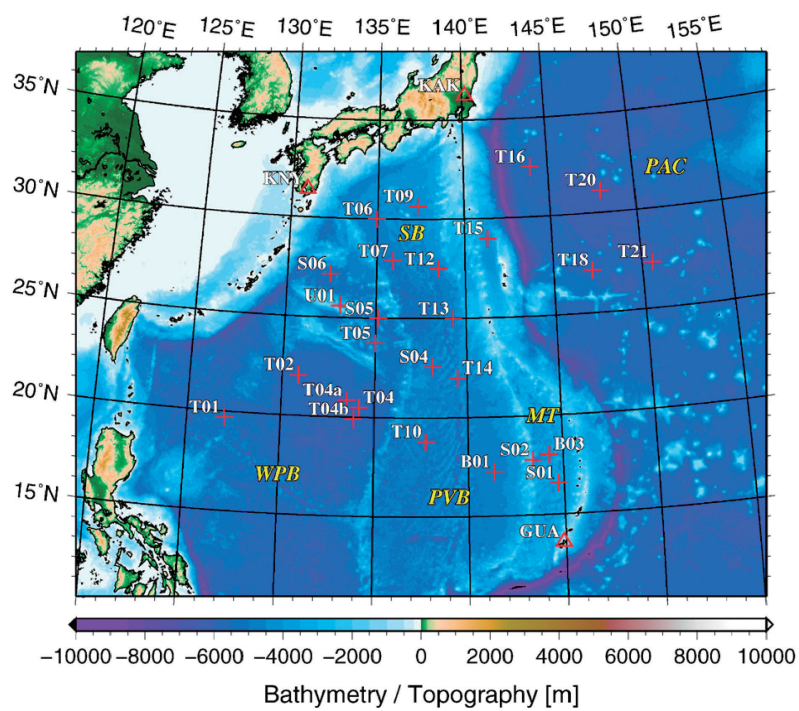

Fig. 8. Location of the seafloor MT sites (red crosses) in the Philippine Sea and West Pacific Ocean superimposed on a bathymetric map. ${ }^{43)}$ The sites whose names start with T, B, S, and $\mathrm{U}$ are those collected through the SSP and from other experiments, ${ }^{91), 107), 108)}$ respectively. Red triangles mark the location of geomagnetic observatories from which data were used as remote references for the response estimation. PAC denotes Pacific Plate; MT, Mariana Trough; SB, Shikoku Basin; PVB, Parece Vela Basin; and WPB, West Philippine Basin.

knowledge suggests that the application of the decomposition method, which assumes that distortion can be expressed by a real tensor operated on the impedance, is not appropriate in this case, because distortion due to the seafloor topographic effects is mostly inductive and generally needs to be expressed by a complex tensor. ${ }^{82)}$ The result of the $2 \mathrm{D}$ inversion (Fig. 7b) was further compared with the seismic result obtained from the same area, revealing that the moderately conducting zone of approximately $0.03 \mathrm{~S} / \mathrm{m}$ (about $30 \Omega \mathrm{m}$ in the unit of resistivity used in Fig. 7) corresponded to the low seismic velocity layer at depths around $60 \mathrm{~km}$. These seismic and electrical signatures are supposed to characterize the oceanic asthenosphere below the high-velocity and more resistive lithosphere. However, it is rather difficult to obtain clear and conclusive results from this observation because the seafloor sites cover only part of the swell. It is also suggested that $3 \mathrm{D}$ topographic and coastline effects have to be considered in inversion analyses for a more detailed and quantitative interpretation.

A series of similar studies has been carried out to image the mantle beneath an active hotspot chain in the French Polynesian super swell by EM exploration in $1989,{ }^{51)}$ and by seismic tomography from 2003 
to 2005. ${ }^{83)}$ For further investigation of the French Polynesian super swell, a joint seafloor seismic and EM observation, called the TIARES (Tomographic Investigation by seafloor ARray Experiment for the Society hotspot) project, was performed from February 2009 to December 2010, focusing on the Society hotspot area and its vicinity, where nine pairs of broadband ocean bottom seismometers (BBOBS) and OBEMs were collocated. ${ }^{84)}$ All instruments have now been successfully recovered and data analysis is being carried out by both seismic and EM teams.

4.3 EM exploration beneath subduction zones. The subduction of oceanic plates transports near-surface materials such as water, sediments and crustal rocks deep into the mantle. The addition of these materials is thought to play significant roles in major tectonic processes (including thrust earthquakes, arc volcanism, and back-arc opening) in the subduction zone and the evolution of the Earth. Therefore a number of EM explorations have been carried out in various subduction zone areas to study mantle structures and tectonic processes. Some studies began over 60 years ago, especially in the region containing the Japanese island arc. $\left.{ }^{85}\right)$

Partly because the computational capability was limited and partly because the actual geometry of the island arc system is almost $2 \mathrm{D}$ in some cases, even in recent works observations are still made in a $1 \mathrm{D}$ array (along a line) that was originally designed for modeling and inversion in a 2D framework. ${ }^{87), 88)}$ Such an inversion sometimes results in a model with a very strong lateral contrast of nearly two orders of magnitude or more, even after the effects of the 3D topography (the bathymetry and coastline effects) are removed. We should note that diagonal elements of the impedance tensor, which are ignored in a 2D approximation, have to be explained. However, past works did not provide such a quantitative explanation for the ignored diagonal elements, because fits of the calculated to observed responses were evaluated only by root-mean-squared (RMS) misfits between off-diagonal elements of the model impedances, which were obtained from a 2D inversion and observed impedances. Even after an optimum model is obtained by $2 \mathrm{D}$ inversion, it is possible to examine 3-dimensionality of the conductivity anomaly by $3 \mathrm{D}$ forward modeling. ${ }^{89)}$ More careful treatment of $3 \mathrm{D}$ effects is also necessary than that for observations in open oceans, due to the rough bathymetry and complex coastlines in subduction zones.

A new approach has been attempted in the western Pacific subduction zone on both sides of the
Izu-Bonin-Mariana arc to probe the mantle structure down to the subducted Pacific slab stagnating in the mantle transition zone (MTZ). ${ }^{90)}$ The project is called the Stagnant Slab Project (SSP). Observation sites (seismic and EM) were distributed in a $2 \mathrm{D}$ array as shown in Fig. 8, as a 3D interpretation was originally intended. Many of the physical parameters such as temperature, pressure, and chemical composition vary vertically to a first order approximation. Therefore, it is considered effective to separate the $3 \mathrm{D}$ electrical conductivity distribution into a 1D reference model and lateral perturbation as

$$
\sigma_{3 D}(x, y, z)=\sigma_{1 D}(z)+\Delta \sigma(x, y ; z),
$$

where $\sigma_{3 D}, \sigma_{1 D}$, and $\Delta \sigma$ denote the $3 \mathrm{D}$ distribution, $1 \mathrm{D}$ reference model and lateral perturbation of the electrical conductivity in the Cartesian coordinate system, respectively. If a good estimation of $\sigma_{1 D}$ is obtained so as to minimize the variance of $\Delta \sigma$, it is expected to be a good a priori model for $3 \mathrm{D}$ inversion. ${ }^{56)}$

A regional reference model was estimated for the Philippine Sea and the northwest Pacific Ocean as shown in Fig. 9. ${ }^{43)}$ As is common for models obtained from seafloor MT observations, each model shows the presence of a highly conductive layer in the upper mantle below the very resistive layer. These layers are known as the electrical asthenosphere and lithosphere, respectively, because the transition from low to high conductivity occurs at around the depth where the lithosphere-asthenosphere boundary (LAB) is supposed to exist. ${ }^{21}$ ) The age of the seafloor where the observation sites were located ranges between 20 and $70 \mathrm{Ma}$ for the Philippine sea and 140 and $155 \mathrm{Ma}$ for the western Pacific case. Therefore the difference in the electrical lithosphere thickness between the two results is qualitatively consistent with the concept of the lithosphere cooling over time. ${ }^{43)}$ A more detailed examination based on dividing the Philippine Sea into two basins (the Shikoku-Parece Vela and the west Philippine basins) showed the same age dependence. However, we recently found that the age dependence of electrical conductivity structures in the oceanic mantle is quite complex as shown in the next section.

A 3D inversion is still not straightforward after estimating the reference model $\sigma_{1 \mathrm{D}}$. The effect of the seafloor topography should be incorporated into the inversion because the high conductivity of seawater makes the induction number $M$ in Eq. [5] relatively large even for a small topography. Furthermore the effect of the topography cannot be regarded as 

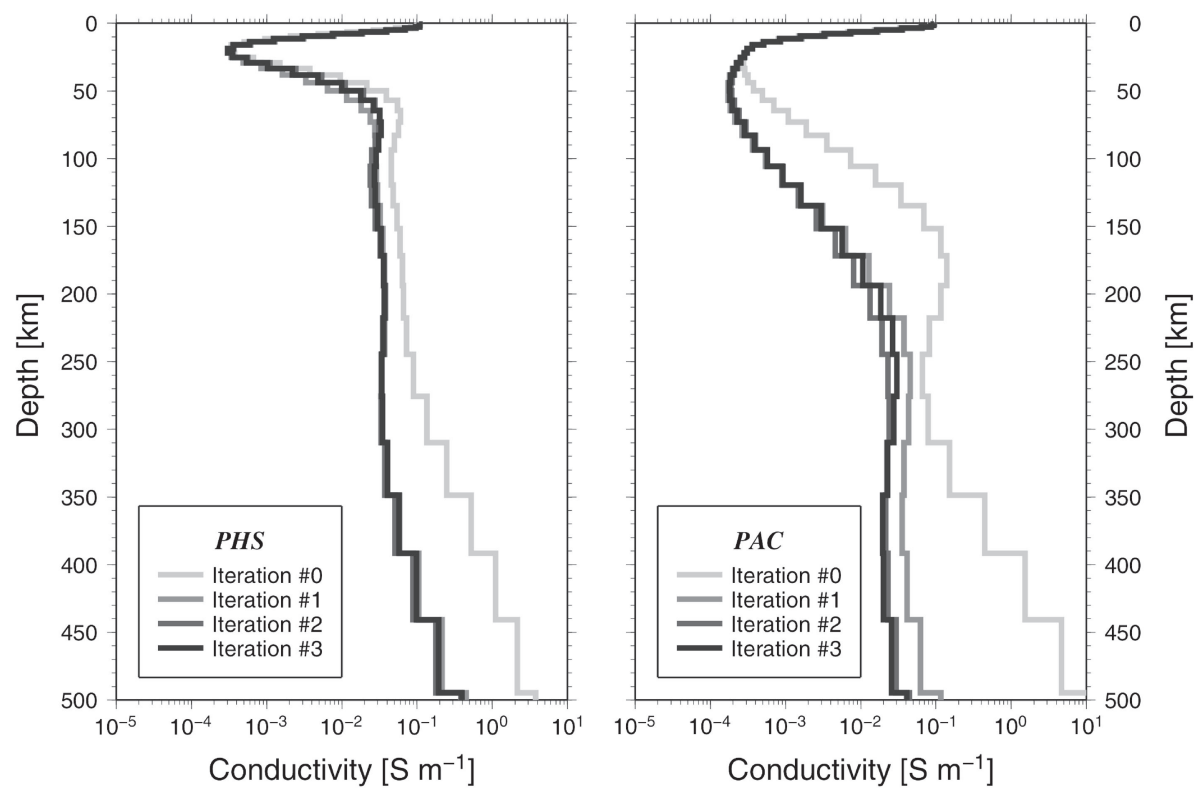

Fig. 9. 1D mantle models for the Philippine Sea mantle (left) and the Pacific mantle (right). Each model was obtained by iterating the impedance averaging; ${ }^{15)} 1 \mathrm{D}$ Occam inversion of averaged impedance and topographic correction. The final model is shown by a black line. ${ }^{43)}$

static ${ }^{81)}$ but should generally be treated as inductive. The effect is therefore supposed to depend strongly on frequency and also on the deep conductivity structure. To evaluate the near-site topographic effect, modeling with a fine grid is required, while a large area should be considered to accurately evaluate the coastline effects. At present, topographic effects are evaluated in two stages as described in Section 3, i.e., correction of local topographic effects in fine grids and incorporation of large scale topographic effects in the forward calculation of the inversion with coarser grids. ${ }^{63), 64)}$ The most recent 3D inversion result ${ }^{65)}$ shows a weak lateral conductivity contrast of less than one order of magnitude (Fig. 10). This result was obtained by assuming an error floor for the diagonal elements in two steps (25\% and $10 \%)$ to avoid overfitting to data with exceptionally small error bars. In magnetotellurics, the model fit to observation data is evaluated by a RMS misfit,

$R M S$

$$
=\sqrt{\frac{1}{N} \sum_{k, l} \sum_{i, j}\left|\frac{\log Z_{i j}^{o b s}\left(\mathbf{r}_{k} ; \omega_{l}\right)-\log Z_{i j}^{c a l}\left(\mathbf{r}_{k} ; \omega_{l}\right)}{e_{i j}\left(\mathbf{r}_{k} ; \omega_{l}\right)}\right|^{2}},
$$

where $Z_{i j}{ }^{o b s}$ and $Z_{i j}{ }^{c a l}$ are the $i j^{\prime}$ th $(i=1,2 ; j=1,2)$ elements of the observed and calculated impedance tensor for observation site $\mathbf{r}_{k}$ and frequency $\omega_{l}$, and $e_{i j}$ is a percentage observation error for the corresponding element, site and frequency. Therefore, when the model explains the observation within the error bar on average, the RMS misfit is smaller than unity. The RMS misfit for the starting model (with $\sigma_{1 D}$ below $3 \mathrm{D}$ ocean/land) was reduced from 14.5 to about 5.5 by setting the initial error floor, but was reduced to about 2.8 in the first iteration step. The error floor was subsequently decreased and the RMS misfit changed from 4.5 to 3.6. This means that the variance reduction by inversion was about $60 \%$, which is consistent with the relatively weak lateral contrast in the inverted model. However, the RMS misfit between the calculated and observed responses is still significantly greater than one, which means further improvement of the model is required to account for all observations within the error margins.

4.4 EM explorations of normal oceanic mantle. During the past few decades, most marine EM explorations were attempted to study electrical conductivity distributions in the upper mantle near mid-oceanic ridges, hot-spot regions or subduction zones, where distinct lateral heterogeneities can be expected due to the vertical movement of mantle materials. These studies have revealed a wide variation in the 'electrical conductivity anomaly' in the upper mantle across different regions, as shown 
(a)

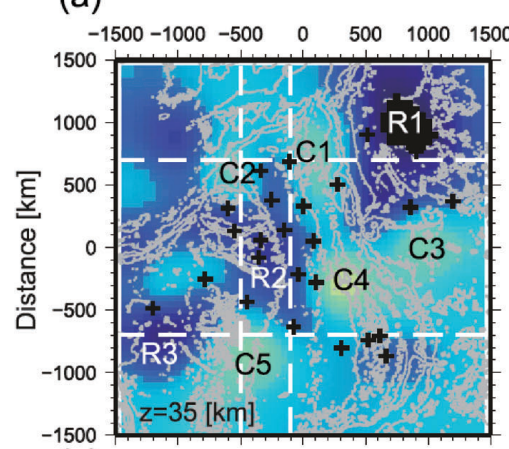

(c)

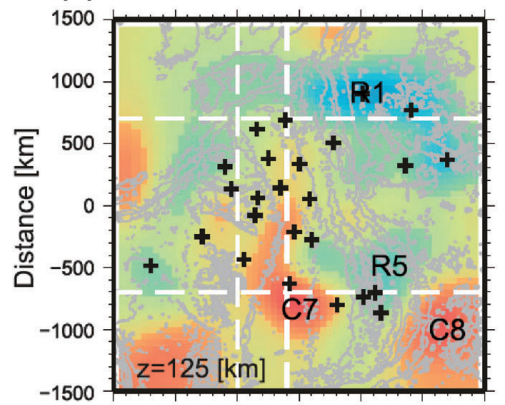

(e) R3

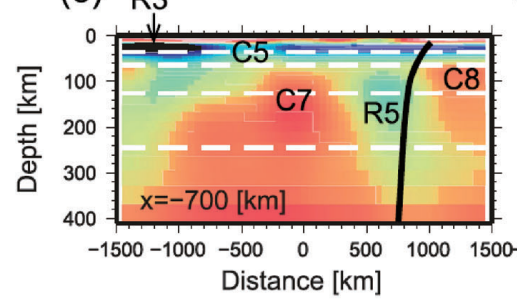

(b)

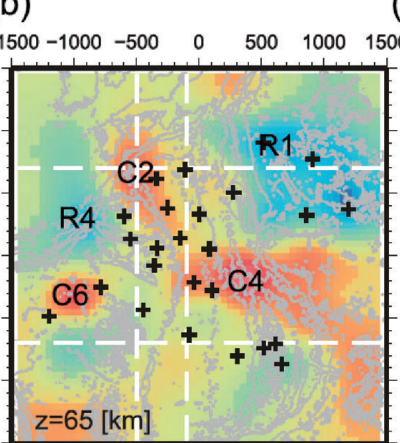

(d)

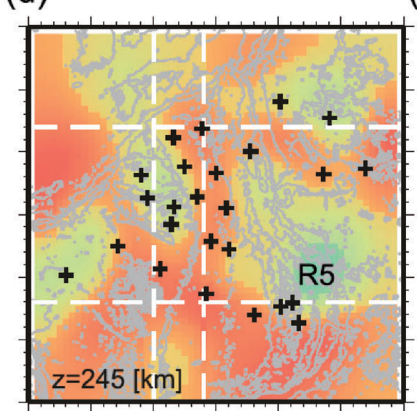

(f)

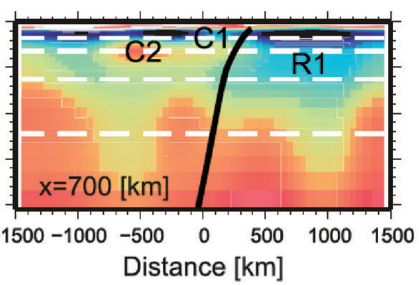

(g)。

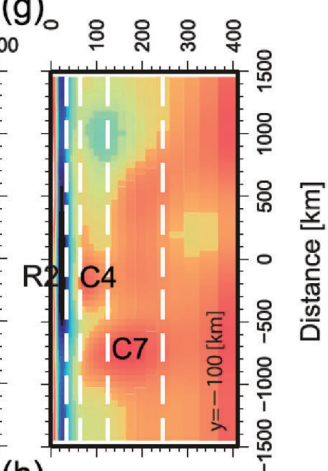

(h)

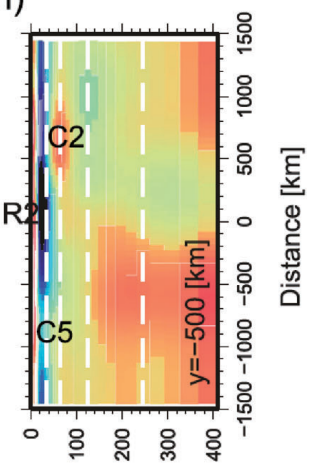

[ux] uұdə0

Log Resistivity [Ohm m]

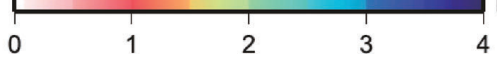

Fig. 10. 3D representation of the conductivity model inverted from seafloor EM data from the observation array shown in Fig. $8{ }^{65)}$ Black crosses mark the location of the seafloor MT sites. Gray lines indicate the bathymetric contours. Plan views are presented at depths of (a) 35, (b) 65, (c) 125, and (d) $245 \mathrm{~km}$, respectively. Dashed lines indicate the location of the cross sections for (e) $\mathrm{x}=-700 \mathrm{~km},(\mathrm{f}) \mathrm{x}=700 \mathrm{~km},(\mathrm{~g}) \mathrm{y}=-100 \mathrm{~km}$, and (h) $\mathrm{y}=-500 \mathrm{~km}$, respectively. White dashed lines in the cross sections indicate the level of the plan views. Black lines in (e) and (f) indicate the slab surface ${ }^{109)} \mathrm{C} 1-\mathrm{C} 8$ and $\mathrm{R} 1-\mathrm{R} 5$ indicate the locations of the distinct conductive and resistive anomalies, respectively.

in the previous sections. However, 'conductivity anomaly' is ambiguous terminology because no standard model such as the global reference model in seismology has been established for the electrical conductivity structure in the Earth. Thus, some of the most recent research projects have focused on normal oceanic mantle, where the oceanic plate is moving horizontally and the mantle structure is supposed to reflect simply a result of cooling with age.

In order to investigate the normal mantle structure below the old oceanic crust, a long-term array observation was carried out in the northwest Pacific Ocean from June 2010 to September 2014, using a number of ocean bottom seismic and EM instruments (the Normal Oceanic Mantle — NOMan Project). The observation consisted of two seafloor arrays in Area A and Area B (Fig. 11a) set to the northwest and southeast of the Shatsky Rise, respectively. ${ }^{92)}$ The Shatsky Rise was not included in the study area within the coverage of observation arrays, because the mantle below it may have features related to the volcanic activity at its formation period.

Although only a preliminary analysis is currently available, a remarkable result has been obtained in the NOMan Project. ${ }^{93), 94)}$ Figure 11b 

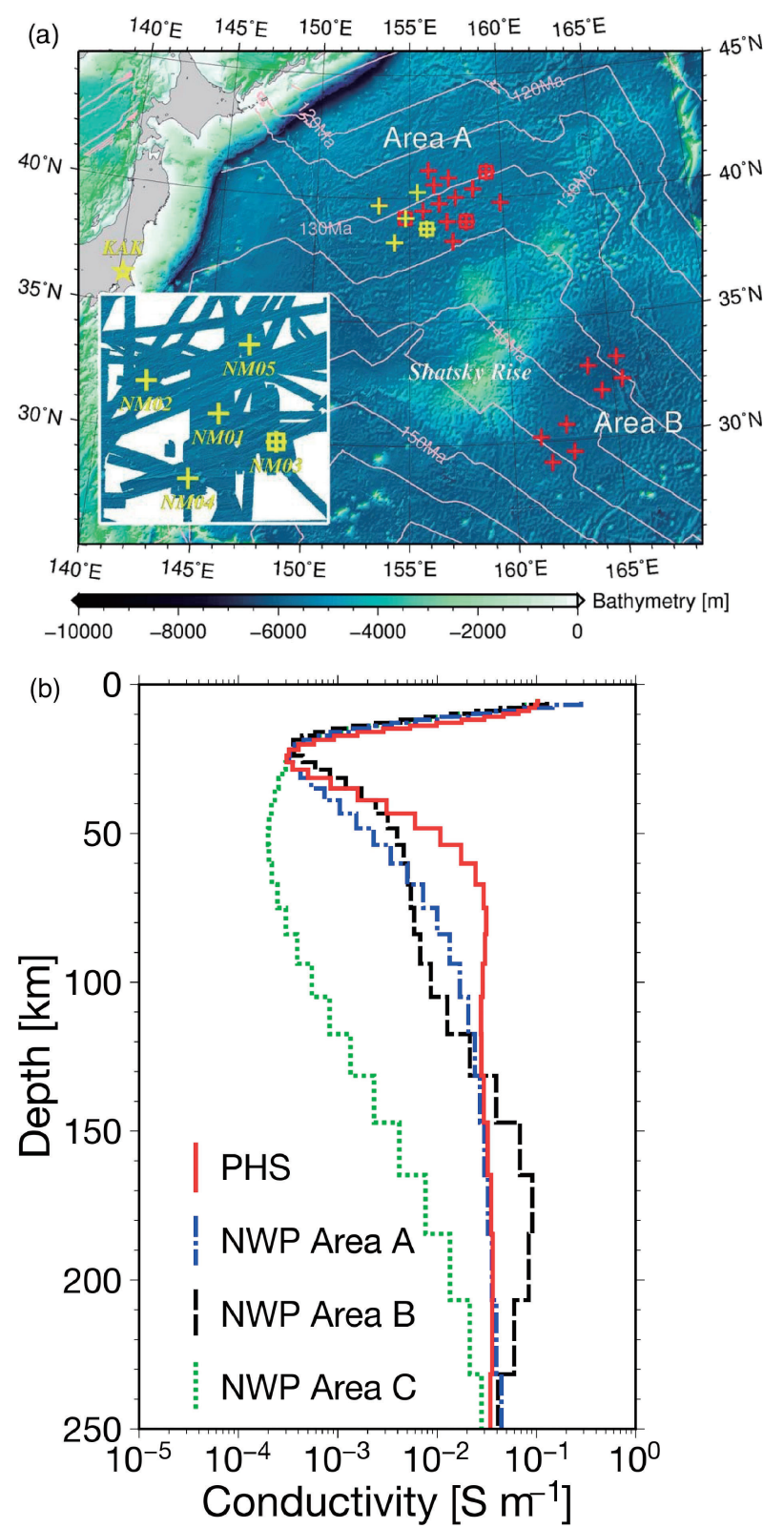

Fig. 11. (a) Location of the observation sites of the NOMan Project superimposed on a bathymetry map. Crosses, squares, and a star indicate the sites of OBEMs, EFOSs, and the Kakioka geomagnetic observatory (KAK), respectively. Yellow crosses and squares indicate the sites of the pilot survey whose data were already analyzed. ${ }^{93)}$ Contour lines indicate seafloor age. ${ }^{110)}$ The inset shows a close-up of the pilot survey area, but the bathymetry map is based on the collection of multi-narrow beam echo sounding data (no available data in the white area). Labels are the site names. (b) 1D electrical conductivity structure profiles for the four areas, PHS and areas A, B, and C in the northwest Pacific, denoted by red, blue, black and green lines, respectively. ${ }^{93)}$ Significant variation is seen at the uppermost upper mantle, but conductivity values for these regions are almost identical at a depth of about $200 \mathrm{~km}$. shows the $1 \mathrm{D}$ conductivity profiles obtained from preliminary data in Area A and in Area B together with two other profiles for the Philippine Sea (PHS) and the western Pacific (hereafter referred to as Area C) from the SSP result (see Fig. 9). The mean seafloor ages are about $0-60,127-133,135-145$ and 140-155 Ma for PHS and Areas A, B and C in the western Pacific, respectively. As shown in this figure, the thickness of the shallower resistive $(<0.01 \mathrm{~S} / \mathrm{m})$ layer below Area A is about $50-60 \mathrm{~km}$, which is only slightly thicker than that below PHS where the thickness is about $40 \mathrm{~km}$. Area B shows a electrical structure different from that of Area A with lower and thicker resistive layers above a more conductive deeper section, despite the seafloor age being older than that of Area A by only $10 \mathrm{Ma}$ or so. On the other hand, the mantle below Area C, which has a mean seafloor age $20 \mathrm{Ma}$ older than area $\mathrm{A}$, is quite different in that it is highly resistive down to a depth of about $180 \mathrm{~km}$.

A most recent result from the NoMelt Project in $70 \mathrm{Ma}$ old central Pacific ${ }^{95)}$ shows almost 1D feature with about $80 \mathrm{~km}$ thick resistive $(<0.001 \mathrm{~S} / \mathrm{m})$ layer above more conductive $(>0.02 \mathrm{~S} / \mathrm{m})$ layer. Whole data were inverted both in isotropc and anisotropic 2-D frameworks, but no significant anisotropy was inferred.

Another result has been reported regarding the Eastern Pacific Ocean off the coast of Nicaragua, where seafloor MT data were obtained along a line nearly perpendicular to the middle America Trench axis (Fig. 12a). ${ }^{96}$ ) The MT data were inverted to a $2 \mathrm{D}$ anisotropic conductivity section below the 23$24 \mathrm{Ma}$ old Cocos oceanic plate. The result revealed an enhanced conductor between depths of 45 and $70 \mathrm{~km}$ (Fig. 12b). The top of this conductive layer is significantly shallower than in the case of the young oceanic mantle near the ridge of the MELT result (Section 4.1) and similar depth to that for the Philippine Sea. As for electrical anisotropy, the Nicaraguan and MELT results are consistent, showing higher conductivity in the direction parallel to the tectonic motion. These results, however, are the interpretations of anisotropies with different origins: one (the MELT case) is the anisotropic mobility of charge carriers (protons) in hydrated mantle minerals ${ }^{72}$ ) and the other (the Nicaraguan case) the anisotropic connectivity of partial melt caused by shearing. ${ }^{96)}$

Thus, these results show rather small spatial variations in electrical structure between regions of younger oceanic mantle, while large variability is 


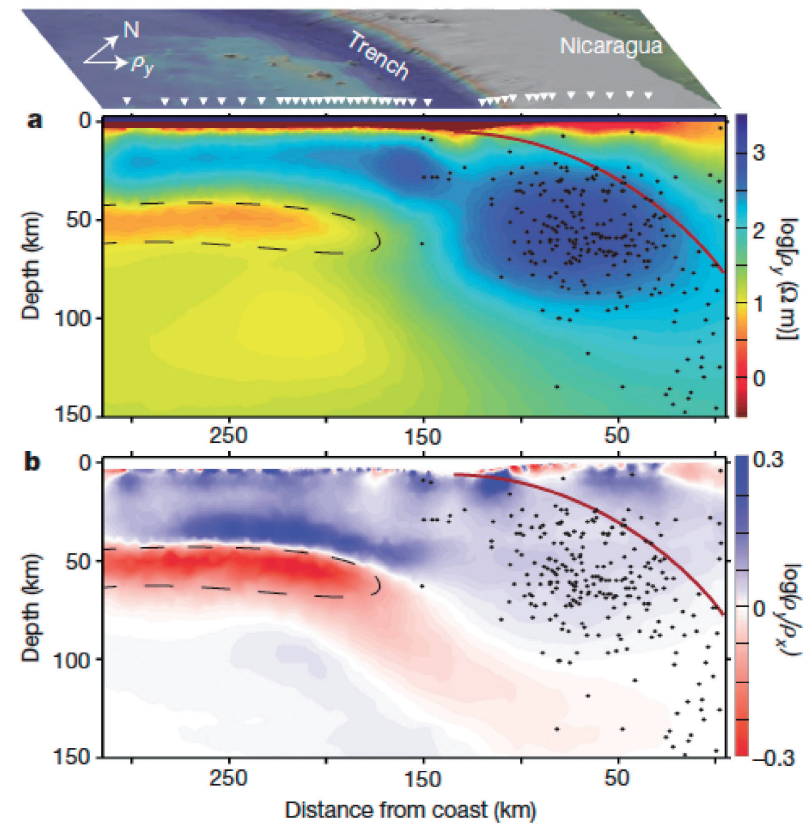

Fig. 12. Resistivity model obtained from an anisotropic 2D inversion of the seafloor MT data. ${ }^{96)}$ At the top is the surface view; arrows show the north direction and $y$-direction of resistivity, and inverted triangles denote seafloor MT station locations. (a) The electrical resistivity in the direction parallel to the plate motion ( $y$-direction). The color scale shows the log of resistivity. The dark red line is a model of the top of the subducting slab. ${ }^{109)}$ Earthquake hypocenters from up to $50 \mathrm{~km}$ off-axis are shown as black circles (from the USGS/NEIC catalogue). The region enclosed by the dashed black line is where the model is at least 1.5 times more conductive in the direction parallel to the plate motion. (b) Resistivity ratio for the platemotion-parallel ( $y$-direction) to trench-axis-parallel ( $x$-direction) model components. The color scale gives the log of the ratio, and the plot shows the strong anisotropy of the conductive layer at depths of $45-70 \mathrm{~km}$ (red regions: $150 \mathrm{~km}$ offshore). The deeper mantle beneath the conductive layer is isotropic.

seen across regions of older oceanic mantle. Although observational evidence has been obtained from a limited number of regions, the results may indicate that the old oceanic mantle structure is determined not simply by the cooling of the lithosphere but also by an additional mechanism. Redistribution of the melt due to plate bending stress near the outer rise ${ }^{97)}$ is a possible cause of such spatial variability.

\section{Discussions and remaining questions}

As shown in this review, there has been significant progress in the exploration of the oceanic mantle structures through both observations and inversions of seafloor EM data. High quality data are now available from sea floor EM observations conducted at a number of sites in several regions. It is now possible to invert these data sets to $3 \mathrm{D}$ models of electrical conductivity distribution. However, we must note the importance of making further sustained effort to obtain more reliable results through EM explorations. This is simply because any sophisticated physical interpretation of observation results will be meaningless if the inversion results include artifacts. In fact, there still remain unsolved questions that need to be addressed to better explore the oceanic mantle, as discussed below.

There exists a well-known trade-off between the observation error and the model fit: if the error level of a given dataset of observations is high, it is easy to find a model that explains all the observations within the error margins. The resulting model parameters allow a large variance and thus the model is quite ambiguous. In other words, a sufficiently low error level is required to obtain an unambiguous model. In the field example shown in Section 4.3, the error floor was set as small as $2.5 \%$ or so, but the resulting RMS (as defined by Eq. [12]) was still as large as 5.5 even for the best regional 1D profile from an observation array in the Philippine Sea. ${ }^{43)}$ This large misfit, or at least some part of it, could be explained by effects of $3 \mathrm{D}$ heterogeneity in the mantle. If the error level was set three times larger, the RMS would be smaller than one and thus the overall features of the observed impedances would be able to be explained simply by the $1 \mathrm{D}$ conductivity model below a heterogeneous ocean within the error bars. By introducing lateral heterogeneity as described in Eq. [11], the total RMS misfit is reduced to about 3.6 by a $3 \mathrm{D}$ inversion with an assumed error floor of $2.5 \%{ }^{65)}$ Although the reduction in the misfit is quite significant, it is still far above the level of 1.0. Further studies are necessary to clarify the cause of this excess misfit and to reduce it. There also is a trade-off between the spatial resolution and the accuracy of parameters estimated by inversion. There is no established way to quantitatively present the resolution and uncertainty of inverted parameters in 2D or 3D case, although a possible presentation of parametric uncertainty was proposed for $1 \mathrm{D}$ case. $^{43)}$

EM response functions change smoothly with frequency due to the diffusive nature of EM induction. If there is a discontinuous feature in the frequency dependence, we should suspect a contribution from effects other than EM induction. Figure 13 gives an example of such a feature, which shows an abrupt change in the squared amplitude (termed the apparent resistivity) and phase of the impedance at frequencies of about $10^{-4} \mathrm{~Hz}$ or lower. This feature 


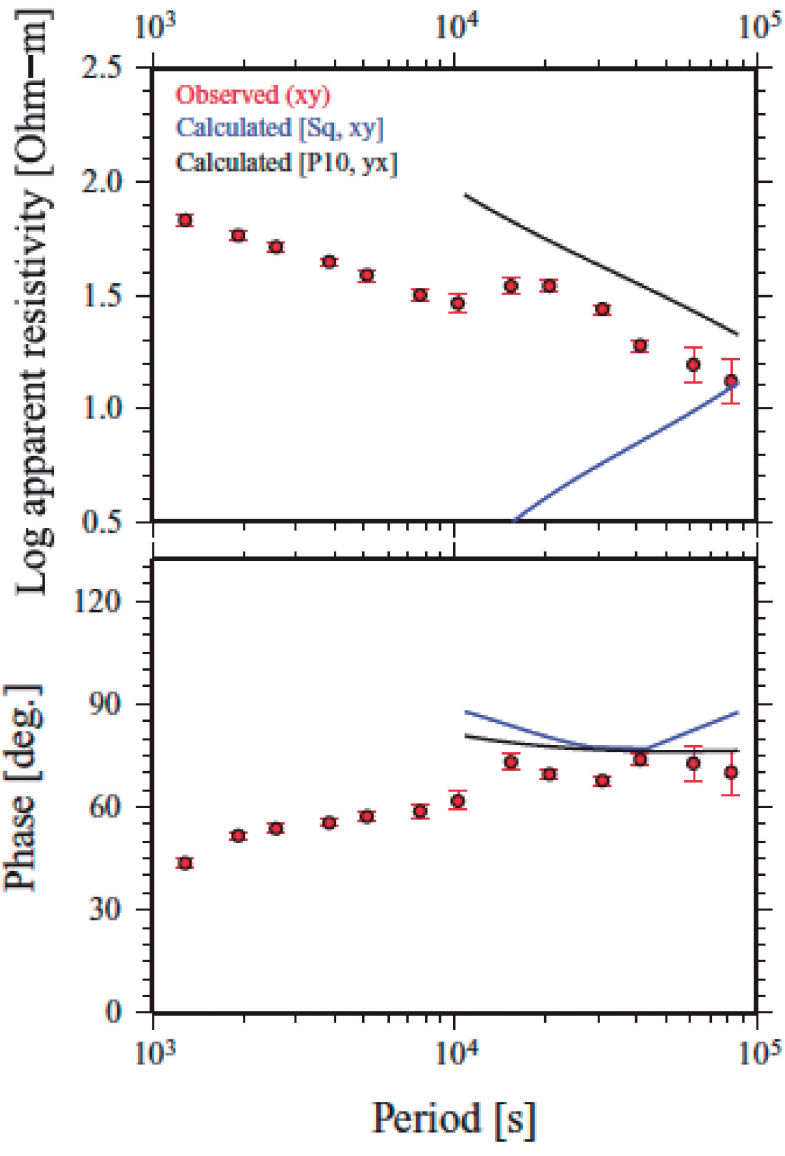

Fig. 13. Comparison of observed and calculated MT responses, the apparent resistivity (squared amplitude) and phase, at a seafloor site in the Philippine Sea. ${ }^{99)}$ The observed responses (red dots) and that of the calculated responses assuming an Sq source (blue line) are shown. The MT response with a ring current source that simulates a laterally plane source (black line) is also shown as a reference. Qualitatively, typical behaviors in the observed response can be explained by a mixture of these components.

is fairly commonly observed in EM responses at the seafloor and is usually ascribed to the deep mantle conductivity structure. ${ }^{51), 80)}$ A recent study ${ }^{99)}$ found that such a feature is reflecting the source characteristics of $\mathrm{Sq}$ (solar-quiet geomagnetic daily variation) and its higher harmonics. Spectra of the EM field measured at the seafloor contain line spectra due to Sq harmonics and ocean tidal constituents, but these components were removed from the original time series by a least-squares fit before calculating the EM response of Fig. 13. ${ }^{43)}$ Since the code for spectral analyses applies statistics to obtain robust estimates of response functions, ${ }^{7)}$ this result suggests that spectral components showing the source field feature of $\mathrm{Sq}$ are the majority in the period band between
$10^{4} \mathrm{~s}$ and one day, while it is well known that the source field for dominant spectral components in the shorter period band can be approximated by a laterally plane wave. It is quite possible, therefore, that a set of wide band responses obtained from seafloor EM observation such as those shown in Fig. 13 consists of components with two different kinds of dominant source field characteristics, although modeling and inversion are performed by assuming a plane source field for both period bands. This could result in an inaccurate estimation of the structure of the deeper upper mantle. One possible way to overcome this problem is to do a forward calculation of the longer period band by rigorously taking the source field features into consideration. Such modeling in a global induction approach ${ }^{86)}$ is rather straightforward, but it is difficult to realize sufficient spatial resolution for a regional study. Therefore, another solution for a regional induction approach is necessary. Considering the possible presence of components with a plane wave source field in the longer period band, it is worth attempting to develop a method of spectral estimation that can extract statistically minor spectral components, distinguishing spectral components by source field characteristics.

In general, the electrical conductivity of the Earth tends to increase with depth, which is mostly due to the effect of temperature on the electrical conduction of silicate rock-forming minerals. However, the high conductivity observed in the oceanic upper mantle (the electrical asthenosphere), which typically has values of $0.01-0.1 \mathrm{~S} / \mathrm{m}$, cannot be explained simply by the normal mantle geotherm but requires an additional conduction mechanism. The interpretation of EM exploration results may provide certain information on the amount of carrier for additional conduction, such as partially molten materials and hydrogen in minerals. However, in many cases, the solution of such an interpretation is not unique. The resulting conductivity profile can be equally translated into either a profile of the melt fractions or a profile of the hydrogen content, ${ }^{100)}$ and therefore interpretation of EM data alone does not adequately constrain the physical condition of the upper mantle. For this reason it must be combined with other observations such as seismic exploration. As such, the joint interpretation of seismic and EM exploration results is able to determine the structure of and provide useful information on the upper mantle. ${ }^{94), 98)}$ To this end there are seafloor studies using collocated seismic and EM instruments to make 
such an interpretation is possible. ${ }^{84), 91)}$ However, to date, such array observations have only been carried out in areas covering a fraction of the entire ocean and many seismic and EM array studies were performed separately. Thus, observational efforts should be continued, for which international collaboration is efficient, but the standardization of array design is indispensable.

Seismic anisotropy is one of the most important properties characterizing the stress condition in the oceanic asthenosphere. ${ }^{101)}$ It has been suggested that the conductivity of hydrous olivine also shows anisotropy due to the lattice preferred orientation. ${ }^{4)}$ However, a simple numerical modeling study ${ }^{102)}$ suggested that electrical anisotropy in a resistive layer such as the lithosphere is unlikely to be detected by the MT method due to its low sensitivity. The electrical conductivity of the asthenosphere is expected to show anisotropic characteristics if the origin of the asthenosphere is the hydration of mantle materials. ${ }^{31)}$ Actually, several seafloor EM exploration studies have revealed anisotropic features of the uppermost oceanic mantle, possibly corresponding to the hydrated asthenosphere. ${ }^{72)}$ However, the electrical anisotropy of the asthenosphere is still a controversial issue. For example, there is a laboratory result for hydrous olivine conduction that showed very weak anisotropy. ${ }^{103)}$ This implies that the asthenospheric electrical anisotropy, if any observation suggests, should be ascribed to other mechanism such as macroscopic heterogeneity. This problem has not been settled yet, because the most recent laboratory experiment showed intense anisotropy exceeding one order of magnitude at higher temperatures. ${ }^{104)}$ On the other hand, the horizontal shear causes electrical anisotropy due to the anisotropic connectivity of the melt phase in a partially molten asthenosphere, a mechanism which has been used to interpret another recent observational result of asthenospheric anisotropy. ${ }^{96)}$ Furthermore, it is more difficult to invert observed EM responses into an anisotropic conductivity model in a 3D setting than inverting them to an isotropic model. In most cases of previous studies, anisotropic inversions were performed in a $2 \mathrm{D}$ framework, assuming the axis of anisotropy to be either parallel or perpendicular to the $2 \mathrm{D}$ strike direction. In principle, the anisotropic feature in the MT impedance can be attributed to either the intrinsic anisotropy of the Earth material or the lateral heterogeneity of the isotropic Earth structure, and it is generally difficult to distinguish between these especially in a 3D framework. ${ }^{105)}$ Even in a $2 \mathrm{D}$ framework, accurate inversion is difficult in some cases particularly when the anisotropic axis does not coincide with the $2 \mathrm{D}$ structural strike. ${ }^{106}$ ) Modeling and inversion including anisotropy needs further more detailed and careful study, as it might be a cause for the residual misfit between observed EM responses and those calculated for a final model of a $3 \mathrm{D}$ inversion.

\section{Concluding remarks}

This paper reviewed the recent methodological progress in EM explorations of the oceanic mantle. Due to advancements in instrumental development, long-term, high-quality EM data are now available from an observation array in the deep ocean consisting of over ten sites. There has also been a rapid advance in processing, analyzing and inverting seafloor EM data. Now EM methods can be regarded as among the most powerful tools for exploring deep oceanic mantle. With such progress in both observation and analysis, we can expect new insights into the oceanic mantle to be made possible by EM explorations in the coming decade. This paper mostly focused on instrumentation, observation, data processing and inversion, each of which plays an essential role in obtaining reliable results from EM explorations. We can derive useful information from the resulting models of electrical structure through physical interpretations. However, there still remains the need to further improve every aspect of the method. Sustained efforts with this in mind are of the utmost importance.

\section{Acknowledgments}

The author is deeply indebted to Prof. Yoshio Fukao, M.J.A., for his continuous encouragement. He also thanks two reviewers for their carefully reading the manuscript and providing valuable comments.

\section{References}

1) Cagniard, L. (1953) Basic theory of the magnetotelluric method of geophysical prospecting. Geophysics 18, 605-635.

2) Tikhonov, A. (1950) On determining electrical characteristics of the deep layers of the earth's crust. Dokl. Akad. Nauk. USSR 73, 295-297.

3) Rikitake, T. (1949) A method for studying the relation between the time changes in geomagnetism and Earth current. Bull. Earthq. Res. Inst. Univ. Tokyo 25, 9-13.

4) Yoshino, T. and Katsura, T. (2013) Electrical conductivity of mantle minerals: effects of water in conductivity anomalies. Annu. Rev. Earth Planet. Sci. 41, 605-628. 
5) Pommier, A. (2014) Interpretation of magnetotelluric results using laboratory measurements. Surv. Geophys. 35, 41-84.

6) Chave, A.D. and Jones, A.G. (2012) The Magnetotelluric Method theory and practice. Cambridge Univ. Press, New York.

7) Chave, A.D. and Thomson, D.J. (2004) Bounded influence magnetotelluric response function estimation. Geophys. J. Int. 157, 988-1006.

8) Mackie, R.L. and Madden, T.R. (1993) Threedimensional magnetotelluric inversion using conjugate gradients. Geophys. J. Int. 115, 215-229.

9) Singer, B.Sh. (1995) Method for solution of Maxwell's equations in non-uniform media. Geophys. J. Int. 120, 590-598.

10) Avdeev, D.B. (2005) Three-dimensional electromagnetic modeling and inversion from theory to application. Surv. Geophys. 26, 767-799.

11) Kuvshinov, A.V. (2012) Deep electromagnetic studies from land, sea, and space: progress status in the past 10 years. Surv. Geophys. 33, 169-209.

12) Siripunvaraporn, W. (2012) Three-dimensional magnetotelluric inversion: an introductory guide for developers and users. Surv. Geophys. 33, 5-27.

13) Utada, H. and Munekane, H. (2000) On galvanic distortion of regional three-dimensional impedances. Geophys. J. Int. 140, 385-398.

14) Niblett, E.R. and Sayn Wittgenstein, C. (1960) Variation of electrical conductivity with depth by the magnetotelluric method. Geophysics 25, 998-1008.

15) Berdichevsky, M.M., Vanyan, L.L., Kuznetsov, V.A., Levadny, V.T., Mandelbaum, M.M., Nechaeva, G.P., Ukulessky, B.A., Shilovsky, P.P. and Shpak, I.P. (1980) Geoelectrical model of the Baikal region. Phys. Earth Planet. Inter. 22, 1-11.

16) Ogawa, Y. (2002) On two-dimensional modeling of magnetotelluric field data. Surv. Geophys. 23, 251-272.

17) Filloux, J.H. (1967) An ocean bottom D component magnetometer. Geophysics 32, 978-987.

18) Filloux, J.H. (1974) Electric field recording at seafloor with short span instruments. J. Geomag. Geoelectr. 26, 269-279.

19) Poehls, K.A. and von Herzen, R.P. (1976) Electrical resistivity structure beneath the northwest Atlantic Ocean. Geophys. J. R. Astron. Soc. 47, $331-346$

20) Segawa, J., Yukutake, T., Hamano, Y., Kasuga, T. and Utada, H. (1982) Seafloor measurement of geomagnetic field using newly developed ocean bottom magnetometers. J. Geomag. Geoelectr. 34, 571-585.

21) Filloux, J.H. (1980) Magnetotelluric soundings over the Northeast Pacific may reveal spatial dependence of depth and conductance of the asthenosphere. Earth Planet. Sci. Lett. 46, 244-252.

22) Oldenburg, D.W. (1981) Conductivity structure of oceanic upper mantle beneath the Pacific Plate. Geophys. J. R. Astron. Soc. 65, 359-394.

23) Yukutake, T., Filloux, J.H., Segawa, J., Hamano, Y. and Utada, H. (1983) Preliminary report on a magnetotelluric array study in the Northwest Pacific. J. Geomag. Geoelectr. 35, 575-587.

24) Anderson, D.L. and Spetzler, H. (1970) Partial melting and the low-velocity zone. Phys. Earth Planet. Inter. 3, 62-64.

25) Paulson, A. and Richards, M.A. (2009) On the resolution of radial viscosity structure in modeling long-wavelength post-glacial rebound data. Geophys. J. Int. 179, 1516-1526.

26) Shankland, T.J. and Waff, H.S. (1977) Partial melting and electrical conductivity anomalies in the upper mantle. J. Geophys. Res. 82, 54095417.

27) Karato, S. (1990) The role of hydrogen in the electrical conductivity of the upper mantle. Nature 347, 272-273.

28) Karato, S.-I. (1995) Effects of water on seismic wave velocities in the upper mantle. Proc. Jpn. Acad. Ser. B 71, 61-66.

29) Jackson, I., Fitz Gerald, J.D., Faul, U.H. and Tan, B.H. (2002) Grain-size-sensitive seismic wave attenuation in polycrystalline olivine. J. Geophys. Res. Solid Earth 107, ECV 5-1-ECV 5-16, doi:10.1029/2001JB001225.

30) Gaillard, F., Mohammed, M., Iacono-Marziano, G., Pichavant, M. and Scaillet, B. (2008) Carbonatite melts and electrical conductivity in the asthenosphere. Science 322, 1363-1365.

31) Karato, S.-I. (2012) On the origin of the asthenosphere. Earth Planet. Sci. Lett. 321-322, 95-103.

32) Wang, D., Mookherjee, M., Xu, Y. and Karato, S. (2006) The effect of water on the electrical conductivity of olivine. Nature 443, 977-980.

33) Yoshino, T., Matsuzaki, T., Yomashita, S. and Katsura, T. (2006) Hydrous olivine unable to account for conductivity anomaly at the top of the asthenosphere. Nature 443, 973-976.

34) Constable, S.J. (1990) Marine electromagnetic induction studies. Surv. Geophys. 11, 303-327.

35) Palshin, N.A. (1996) Ocean electromagnetic studies: a review. Surv. Geophys. 17, 455-491.

36) Heinson, G. (1999) Electromagnetic studies of the lithosphere and asthenosphere. Surv. Geophys. 20, 229-255.

37) Baba, K. (2005) Electrical structure in marine settings. Surv. Geophys. 26, 701-731.

38) Ichiki, M., Baba, K., Toh, H. and Fuji-ta, K. (2009) An overview of electrical conductivity structures of the crust and upper mantle beneath the northwestern Pacific, the Japanese Islands, and continental East Asia. Gondwana Res. 16, 545562 .

39) Filloux, J.H. (1987) Instrumentation and experimental methods for oceanic studies. In Geomagnetism vol. 1 (ed. Jacobs, J.A.). Academic Press, San Diego, Calif., pp. 143-246.

40) Hamano, Y., Utada, H., Segawa, J. and Yukutake, T. (1989) Ocean Bottom Electro-magnetometer. Proc. CA symposium 1989, 235-240 (in Japanese).

41) Ichikita, T., Onishi, N. and Utada, H. (1993) Development of an ocean bottom electro-magne- 
tometer. Proc. CA Symposium 1993, 22-29 (in Japanese).

42) Constable, S.C., Orange, A.S., Hoversten, G.M. and Morrison, H.F. (1998) Marine magnetotellurics for petroleum exploration part I: a sea-floor equipment system. Geophysics 63, 816-825.

43) Baba, K., Utada, H., Goto, T., Kasaya, T., Shimizu, H. and Tada, N. (2010) Electrical conductivity imaging of the Philippine Sea upper mantle using seafloor magnetotelluric data. Phys. Earth Planet. Inter. 183, 44-62.

44) The MELT Seismic Team (1998) Imaging the deep seismic structure beneath a mid-ocean ridge: The MELT Experiment. Science 280, 1215-1218.

45) Evans, R.L., Tarits, P., Chave, A.D., White, A., Heinson, G., Filloux, J.H., Toh, H., Seama, N., Utada, H., Booker, J.R. and Unsworth, M.J. (1999) Asymmetric electrical structure in the mantle beneath the East Pacific Rise at 17S. Science 286, 752-755.

46) Utada, H., Baba, K., Shimizu, H., Shiobara, H. and Tada, N. (2013) Ocean bottom measurements of the Earth's electric field using long cable installed by ROV. In Proceedings of the International Symposium on Underwater Technology, IEEE, Tokyo, Art. No. UT2013-1014.

47) Schwalenberg, K. and Edwards, R.N. (2004) The effect of seafloor topography on magnetotelluric fields: an analytical formulation confirmed with numerical results. Geophys. J. Int. 159, 607-621.

48) Heinson, G.S. and Constable, S.J. (1992) The electrical conductivity of the oceanic upper mantle. Geophys. J. Int. 110, 159-179.

49) Tarits, P., Chave, A.D. and Schultz, A. (1993) Comment on 'The electrical conductivity of the oceanic upper mantle' by G. Heinson and S. Constable. Geophys. J. Int. 114, 711-716.

50) Constable, S. and Heinson, G. (1993) In defence of a resistive oceanic upper mantle: reply to a comment by Tarits, Chave and Schultz. Geophys. J. Int. 114, 713-723.

51) Nolasco, R., Tarits, P., Filloux, J.H. and Chave, A.D. (1998) Magnetotelluric imaging off the Society Islands hotspot. J. Geophys. Res. 103, 30287-30309.

52) Baba, K. and Seama, N. (2002) A new technique for the incorporation of seafloor topography in electromagnetic modeling. Geophys. J. Int. 150, 392-402.

53) Matsuno, T., Seama, N. and Baba, K. (2007) A study on correction equations for the effect of seafloor topography on ocean bottom magnetotelluric data. Earth Planets Space 51, 981-986.

54) Koyama, T. (2002) A Study of the electrical conductivity distribution in the mantle by using electric field variations measured by submarine cables. Thesis, University of Tokyo.

55) Utada, H., Koyama, T., Shimizu, H. and Chave, A.D. (2003) A semi-global reference model for electrical conductivity in the mid-mantle beneath the north Pacific region. Geophys. Res. Lett. 30, doi:10.1029/2002GL016092.
56) Newman, G.A. and Alumbaugh, D.L. (2000) Threedimensional magnetotelluric inversion using nonlinear conjugate gradients. Geophys. J. Int. 140, 410-424.

57) Zhang, L.L., Koyama, T., Utada, H., Yu, P. and Wang, J. (2012) A regularized three-dimensional magnetotelluric inversion with a minimum gradient constraint. Geophys. J. Int. 189, 296-316.

58) Rodi, W. and Mackie, R.L. (2001) Nonlinear conjugate gradients algorithm for 2-D magnetotelluric inversion. Geophysics 66, 174-187.

59) Pankratov, O. and Kuvshinov, A. (2010) General formalism for the efficient calculation of derivatives of EM frequency-domain responses and derivatives of the misfit. Geophys. J. Int. 181, 229-249.

60) Siripunvaraporn, W., Egbert, G., Lenbury, Y. and Uyeshima, M. (2005) Three-dimensional magnetotelluric inversion: data-space method. Phys. Earth Planet. Int. 150, 3-14.

61) Avdeev, D. and Avdeeva, A. (2009) 3-D magnetotelluric inversion using a limited-memory quasiNewton optimization. Geophysics 74, F45-F57.

62) Kelbert, A., Meqbel, N., Egbert, G. and Tandon, K. (2014) MoDEM: A modular system for inversion of electromagnetic geophysical data. Comput. Geosci. 66, 40-53.

63) Tada, N., Baba, K., Siripunvaraporn, W., Uyeshima, M. and Utada, H. (2012) Approximate treatment of seafloor topographic effects in threedimensional marine magnetotelluric inversion. Earth Planets Space 64, 1005-1021.

64) Baba, K., Tada, N., Utada, H. and Siripunvaraporn, W. (2013) Practical incorporation of local and regional topography in three-dimensional inversion of deep ocean magnetotelluric data. Geophys. J. Int. 194, 348-361.

65) Tada, N., Baba, K. and Utada, H. (2014) Threedimensional inversion of seafloor magnetotelluric data collected in the Philippine Sea and the western margin of the northwest Pacific Ocean. Geochem. Geophys. Geosyst. 7, 2895-2917, doi:10.1002/2014GC005421.

66) Law, L.K. and Greenhouse, J.P. (1981) Geomagnetic variation sounding of the asthenosphere beneath the Juan de Fuca Ridge. J. Geophys. Res. 86, 967-978.

67) Lilley, F.E.M., Filloux, J.H., Ferguson, I.J., Bindoff, N.L. and Mulhearn, P.J. (1989) The Tasman Project of seafloor magnetotelluric exploration: experiment and observations. Phys. Earth Planet. Inter. 53, 405-421.

68) Shimakawa, Y. and Honkura, Y. (1991) Electrical conductivity structure beneath the Ryukyu trench-arc system and its relation to the subduction of the Philippine sea plate. J. Geomag. Geoelectr. 43, 1-20.

69) Filloux, J.H., Law, L.K., Yukutake, T., Segawa, J., Hamano, Y., Utada, H., White, A., Chave, A., Tarits, P. and Green, A.W. (1989) Offshore EMSLAB: objection, experimental phase and early results. Phys. Earth Planet. Inter. 53, 422- 
431

70) Wannamaker, P.E., Booker, J.R., Filloux, J.H., Jones, A.G., Jiracek, G.R., Chave, A.D., Tarits, P., Waff, H.S., Egbert, G.D., Young, C.T., Stodt, J.A., Martinez, M., Law, L.K., Yukutake, T., Segawa, J., White, A. and Green Jr., A.W. (1989) Magnetotelluric observations across the Juan de Fuca subduction system in the EMSLAB Project. J. Geophys. Res. 94, 14111-14125.

71) Wannamaker, P.E., Booker, J.R., Jones, A.G., Chave, A.D., Filloux, J.H., Waff, H.S. and Law, L.K. (1989) Resistivity cross section through the Juan de Fuca subduction system and Its tectonic implications. J. Geophys. Res. 94, 14127-14144.

72) Evans, R.L., Hirth, G., Baba, K., Forsyth, D., Chave, A. and Mackie, R. (2005) Geophysical evidence from the MELT area for compositional controls on oceanic plates. Nature 437, 249-252.

73) Baba, K., Chave, A.D., Evans, R.L., Hirth, G. and Mackie, R.L. (2006) Mantle dynamics beneath the East Pacific Rise at $17 \mathrm{~S}$ : Insights from the Mantle Electromagnetic and Tomography (MELT) experiment. J. Geophys. Res. 111, B02101, doi:10.1029/2004JB003598.

74) Key, K., Constable, S., Liu, L. and Pommier, A. (2013) Electrical image of passive upwelling beneath the northern East Pacific Rise. Nature 495, 499-502.

75) Baba, K., Tarits, P., Chave, A.D., Evans, R.L., Hirth, G. and Mackie, R.L. (2006) Electrical structure beneath the northern MELT line on the East Pacific Rise at $15^{\circ} 45^{\prime} \mathrm{S}$. Geophys. Res. Lett. 33, L22301, doi:10.1029/2006GL027528.

76) Parsons, B. and Sclater, J.G. (1977) An analysis of the variation of ocean floor bathymetry and heat flow with age. J. Geophys. Res. 82, 803-826.

77) McKenzie, D., Jackson, J. and Priestley, K. (2005) Thermal structure of oceanic and continental lithosphere. Earth Planet. Sci. Lett. 223, 337349.

78) Wilson, J.T. (1961) A possible origin for the Hawaiian Islands. Can. J. Phys. 41, 863-870.

79) Morgan, W.J. (1971) Convection plume in the lower mantle. Nature 230, 42-43.

80) Constable, S.J. and Heinson, G.S. (2004) Hawaiian hot-spot swell structure from seafloor MT sounding. Tectonophys. 389, 111-124.

81) Groom, R.W. and Bailey, R.C. (1989) Decomposition of magnetotelluric impedance tensors in the presence of local three-dimensional galvanic distortion. J. Geophys. Res. 94, 1913-1925.

82) Baba, K. and Chave, A.D. (2005) Correction of seafloor magnetotelluric data for topographic effects during inversion. J. Geophys. Res. 110, B12105, doi:10.1029/2004JB003463.

83) Suetsugu, D., Shiobara, H., Sugioka, H., Fukao, Y. and Kanazawa, T. (2007) Topography of the mantle discontinuities beneath the South Pacific superswell as inferred from broadband waveforms on seafloor. Phys. Earth Planet. Inter. 160, 310 318 .

84) Suetsugu, D., Shiobara, H., Sugioka, H., Ito, A.,
Takehi, I., Kasaya, T., Tada, N., Baba, K., Abe, N., Hamano, Y., Tarits, P., Barriot, J.P. and Reymond, D. (2012) TIARES Project-Tomographic investigation by seafloor array experiment for the Society hotspot. Earth Planets Space 64, doi:10.5047/eps.2011.11.002

85) Rikitake, T., Yokoyama, I. and Hishiyama, Y. (1952) A preliminary study on the anomalous behavior of geomagnetic variations of short period in Japan and its relation to the subterranean structure. Bull. Earthq. Res. Inst. Univ. Tokyo 30, 207-221.

86) Kuvshinov, A. and Utada, H. (2010) Anomaly of the geomagnetic $\mathrm{Sq}$ variation in Japan: effect from 3-D subterranean structure or the ocean effect? Geophys. J. Int. 183, 1239-1247.

87) Booker, J.R., Favetto, A. and Pomposiello, M.C. (2004) Low electrical resistivity associated with plunging of the Nazca flat slab beneath Argentina. Nature 429, 399-403.

88) Matsuno, T., Seama, N., Evans, R.L., Chave, A.D., Baba, K., White, A., Goto, T., Heinson, G., Boren, G., Yoneda, A. and Utada, H. (2010) Upper mantle electrical resistivity structure beneath the central Mariana subduction system. Geochem. Geophys. Geosyst. 11, Q09003, doi:10.1029/2010GC003101.

89) Matsuno, T., Evans, R., Seama, N. and Chave, A.D. (2012) Electromagnetic constraints on a melt region beneath the central Mariana back-arc spreading ridge. Geochem. Geophys. Geosyst. 13, Q10017, doi:10.1029/2012GC004326.

90) Shiobara, H., Baba, K. and Utada, H. (2009) Ocean bottom array probes Stagnant Slab beneath the Philippine sea. EOS Trans. Am. Geophys. Union 90, $70-71$.

91) Seama, N., Baba, K., Utada, H., Toh, H., Tada, N., Ichiki, M. and Matsuno, T. (2007) 1-D electrical conductivity structure beneath the Philippine Sea: Results from an ocean bottom magnetoteluric survey. Phys. Earth Planet. Inter. 162, 2-12.

92) Sager, W.W., Zhang, J., Korenaga, J., Sano, T., Koppers, A.P., Widdowson, M. and Mohoney, J.J. (2013) An immense shield volcano within the Shatsky Rise oceanic plateau, northwest Pacific Ocean. Nat. Geosci. 5, 976-981.

93) Baba, K., Tada, N., Zhang, L.L., Liang, P.F., Shimizu, H. and Utada, H. (2013) Is the electrical conductivity of the western Pacific upper mantle normal? Geochem. Geophys. Geosyst. 14, 49694979.

94) Utada, H. and Baba, K. (2014) Estimating the electrical conductivity of the melt phase of a partially molten asthenosphere from seafloor magnetotelluric sounding data. Phys. Earth Planet. Inter. 227, 41-47.

95) Sarafian, E., Evans, R.L., Collins, J., Elsenbeck, J., Gaetani, G., Gaherty, J., Hirth, G. and Lizarralde, D. (2015) The electrical structure of the central Pacific upper mantle constrained by the NoMelt experiment. Geochem. Geophys. Geosyst. 16, 1115-1132. 
96) Naif, S., Key, K., Constable, S. and Evans, R.L. (2013) Melt-rich channel observed at the lithosphere-asthenosphere boundary. Nature 495, 356-359.

97) Hirano, N., Takahashi, E., Yamamoto, J., Abe, N., Ingle, S.P., Kaneoka, I., Hirata, T., Kimura, J., Ishii, T., Ogawa, Y., Machida, S. and Suyehiro, K. (2006) Volcanism in response to plate flexure. Science 313, 1426-1428.

98) Utada, H., Koyama, T., Obayashi, M. and Fukao, Y. (2009) A joint interpretation of electromagnetic and seismic tomography models suggests the mantle transition zone below Europe is dry. Earth Planet. Sci. Lett. 281, 249-257.

99) Shimizu, H., Yoneda, A., Baba, K., Utada, H. and Palshin, N.A. (2011) Sq effect on the electromagnetic response functions in the period range between $10^{4}$ and $10^{5} \mathrm{~s}$. Geophys. J. Int. 186, 193206.

100) Khan, A. and Shankland, T.J. (2012) A geophysical perspective on mantle water content and melting: Inverting electromagnetic sounding data using laboratory-based electrical conductivity profiles. Earth Planet. Sci. Lett. 317-318, 27-43.

101) Karato, S. (2008) Geodynamic significance of seismic anisotropy of the upper mantle: new insights from laboratory studies. Annu. Rev. Earth Planet. Sci. 36, 59-95.

102) Simpson, F. (2013) Distribution functions for anisotropic electrical resistivities due to hydrogen diffusivity in aligned peridotite and their application to the lithosphere-asthenosphere boundary. Tectonophysics 592, 31-38.

103) Yang, X. (2012) Orientation-related electrical conductivity of hydrous olivine, clinopyroxene and plagioclase and implications for the structure of the lower continental crust and uppermost mantle. Earth Planet. Sci. Lett. 317-318, 241-250.

104) Dai, L. and Karato, S. (2014) High and highly anisotropic electrical conductivity of the asthenosphere due to hydrogen diffusion in olivine. Earth Planet. Sci. Lett. 408, 79-86.

105) Plotkin, V.V. (2011) Inversion of heterogeneous anisotropic magnetotelluric responses. Russ. Geol. Geophys. 53, 829-836.

106) Berdichevsky, M.N. and Pushkarev, P.Y. (2006) Are the crustal and upper mantle conductive zones isotropic or anisotropic? Acta Geophysica 54, 333-342.

107) Baba, K., Seama, N., Goto, T., Ichiki, M., Schwalenberg, K., Utada, H. and Suyehiro, K. (2005) Electrical structure of the upper mantle in the Mariana subduction system. IFREE Rep. 2003-2004, Frontier Res. Earth Evol. 2, JAMSTEC, Yokosuka, Japan, 1-16.

108) Utada, H., Goto, T. and on-board scientists on KR05-05 cruise (2006) R/V KAIREI KR05-05 Cruise Report: Recovery of EFOS-10 and OBEM. JAMSTEC, Yokosuka, Japan.

109) Hayes, G.P., Wald, D.J. and Johnson, R.L. (2012) Slab1.0: A three-dimensional model of global subduction zone geometries. J. Geophys. Res. 117, doi:10.1029/2011JB008524.

110) Meuller, R.D., Sdrolias, M., Gaina, C. and Roest, W.R. (2008) Age, spreading rates, and spreading asymmetry of the world's ocean crust. Geochem. Geophys. Geosyst. 9, Q04006, doi:10.1029/ 2007GC001743.

(Received Dec. 12, 2014; accepted Apr. 12, 2015)

\section{Profile}

Hisashi Utada was born in Ibaraki Prefecture in 1953 and graduated from the University of Tokyo in 1976. He received MSc in 1978 and DSc in 1987 also from the University of Tokyo under the guidance of Prof. Takesi Yukutake. In 1980 he was appointed as Research Associate at Earthquake Research Institute (ERI), the University of Tokyo, and was mostly involved in the study of temporal variations of electromagnetic (EM) observables related to seismic or volcanic activities during the early stage of his research carrier. From September 1987 to August 1988, he carried out post-doctoral research on marine EM exploration by using a controlled source, in collaboration with Professor R. N. Edwards at the Department of Physics, University of Toronto. He was promoted to Associate Professor in 1990 and to Professor in 1999 at ERI, the University

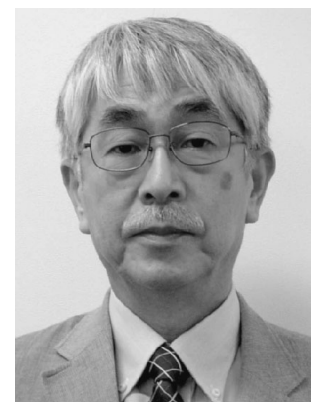
of Tokyo. During the past 25 years, his major research effort has been focused on the study of the structure and dynamics of the Earth's interior based on EM observations, both on- and off-shore, of local, regional and global scales, including development of instruments and data analyses and inversion methods. He has carried out a number of research projects in collaboration with his colleagues not only in Japan but also at foreign institutions. He received the Tanakadate Prize in 1999 from the Society of Geomagnetism and Earth, Planetary and Space Sciences (SGEPSS) and served as the president of SGEPSS from 2007 to 2009. 